\title{
RISK AVERSION, OFFSETTING COMMUNITY EFFECTS, AND COVID-19: EVIDENCE FROM AN INDOOR POLITICAL RALLY
}

\author{
Dhaval M. Dave \\ Andrew I. Friedson \\ Kyutaro Matsuzawa \\ Drew McNichols \\ Connor Redpath \\ Joseph J. Sabia \\ Working Paper 27522 \\ http://www.nber.org/papers/w27522 \\ NATIONAL BUREAU OF ECONOMIC RESEARCH \\ 1050 Massachusetts Avenue \\ Cambridge, MA 02138 \\ July 2020
}

Dr. Sabia acknowledges support from the Center for Health Economics \& Policy Studies (CHEPS) at San Diego State University, including grant support received from the Troesh Family Foundation and the Charles Koch Foundation. The views expressed herein are those of the authors and do not necessarily reflect the views of the National Bureau of Economic Research.

NBER working papers are circulated for discussion and comment purposes. They have not been peerreviewed or been subject to the review by the NBER Board of Directors that accompanies official NBER publications.

(C) 2020 by Dhaval M. Dave, Andrew I. Friedson, Kyutaro Matsuzawa, Drew McNichols, Connor Redpath, and Joseph J. Sabia. All rights reserved. Short sections of text, not to exceed two paragraphs, may be quoted without explicit permission provided that full credit, including $\odot$ notice, is given to the source. 
Risk Aversion, Offsetting Community Effects, and COVID-19: Evidence from an Indoor Political Rally

Dhaval M. Dave, Andrew I. Friedson, Kyutaro Matsuzawa, Drew McNichols, Connor Redpath, and Joseph J. Sabia

NBER Working Paper No. 27522

July 2020, Revised August 2020

JEL No. H75,I1

\section{$\underline{\text { ABSTRACT }}$}

The Centers for Disease Control and Prevention (CDC) deems large indoor gatherings without social distancing the "highest risk" activity for COVID-19 contagion. On June 20, 2020, President Donald J. Trump held his first mass campaign rally following the US coronavirus outbreak at the indoor Bank of Oklahoma (BOK) arena. In the weeks following the event, numerous high-profile national news outlets reported that the Trump rally was "more than likely" the cause of a coronavirus surge in Tulsa county based on time series data. This study is the first to rigorously explore the impacts of this event on social distancing and COVID-19 spread. First, using data from SafeGraph Inc, we show that while non-resident visits to census block groups hosting the Trump event grew by approximately 25 percent, there was no decline in net stay-at-home behavior in Tulsa county, reflecting important offsetting behavioral effects. Then, using data on COVID-19 cases and deaths from the CDC and a synthetic control design, we find little evidence that COVID-19 grew more rapidly in Tulsa County, its border counties, or in the state of Oklahoma than each's estimated counterfactual during the five-week post-treatment period we observe. Difference-in-differences estimates further provide no evidence that COVID-19 rates grew faster in counties that drew relatively larger shares of residents to the event. We conclude that offsetting risk-related behavioral responses to the rally — including voluntary closures of restaurants and bars in downtown Tulsa, increases in stay-at-home behavior, displacement of usual activities of weekend inflows, and smaller-than-expected crowd attendance - may be important mechanisms.

Dhaval M. Dave

Bentley University

Department of Economics

175 Forest Street, AAC 195

Waltham, MA 02452-4705

and IZA

and also NBER

ddave@bentley.edu

Andrew I. Friedson

Department of Economics

University of Colorado Denver

Lawrence Street Center 460T

Campus Box 181

P.O. Box 173364

Denver, CO 80217-3364

andrew.friedson@ucdenver.edu

Kyutaro Matsuzawa

Center for Health Economics and Policy Studies 5500 Campanile Drive

San Diego State University

San Diego, CA

qmatsuzawa@gmail.com
Drew McNichols

Center for Health Economics

\& Policy Studies (CHEPS)

University of San Diego-California

9500 Gilman Drive \#0508

La Jolla, CA 92093-0043

dmcnichols@ucsd.edu

Connor Redpath

Center for Health Economics

\& Policy Studies (CHEPS)

University of California, San Diego

credpath@ucsd.edu

Joseph J. Sabia

San Diego State University

Department of Economics

Center for Health Economics

\& Policy Studies

San Diego, CA 92182

and IZA \& ESSPRI

jsabia@sdsu.edu 


\section{Introduction}

"Coronavirus surge in Tulsa 'more than likely' linked to Trump rally"

- New York Times headline, July 10, $2020^{1}$

"Large in-person gatherings where it is difficult for individuals to remain spaced at least 6 feet apart and attendees travel from outside the local area" are the "highest risk" category of event or gathering for the spread of COVID-19, according to current Centers for Disease Control and Prevention (CDC) guidelines (Centers for Disease Control and Prevention 2020a). Indoor gatherings are viewed as problematic as indoor temperature, airflow and humidity are conductive to the spread of COVID-19 (Allen and Marr, 2020; Contini and Costabile, 2020; Mittal et al., 2020; Setti et al., 2020). Between March 15, 2020 and June 1, 2020, nearly all states and the District of Columbia banned large indoor gatherings such as sporting events and theatre performances (Dave et al., 2020b; Mervosh et al., 2020). ${ }^{2}$

Despite the high-risk categorization of indoor gatherings, some states have rolled back bans on indoor events. For example, as of June 22, 2020 most counties in Nebraska were allowed to hold indoor events as long as attendance did not exceed the maximum of 50 percent of building capacity or 10,000 individuals (Treisman 2020). However, there is very little evidence on the effect of large indoor events on population-level spread of COVID-19,

\footnotetext{
${ }^{1}$ For other similar headlines from around this date, see, for example, articles at Forbes (https://www.forbes.com/sites/tommybeer/2020/07/08/trump-rally-more-than-likely-led-to-coronavirus-spike-intulsa-health-official-says/\#6495ca4924e0), the Washington Post (https://www.washingtonpost.com/nation/2020/07/09/trump-tulsa-rally-coronavirus/), and CNN (https://www.cnn.com/2020/07/08/us/tulsa-covid-trump-rally-contact-tracers-trnd/index.html).

${ }^{2}$ Many large indoor events were cancelled earlier than this. For example, on Thursday March 11, the National Basketball Association (NBA) cancelled a game between the Utah Jazz and Oklahoma City Thunder after a single player tested positive for COVID-19. The game had been scheduled to be played indoors at the Oklahoma City Chesapeake Energy Arena. Later that evening, the NBA suspended the remainder of the 2020 basketball season (Aschburner 2020).
} 
especially during the time when state and local policymakers are determining whether to ease social distancing policies. ${ }^{3}$

To attempt to investigate the risk posed by indoor events, we study President Donald J. Trump's re-election campaign rally, held on June 20, 2020 at the Bank of Oklahoma (BOK) Center and nearby convention center in Tulsa, Oklahoma. While estimates leading up to the rally estimated that attendance would reach up to 100,000 - well over the capacity of the venue, forcing overflow to the nearby convention center (Murphy 2020a; Murphy and Lauer 2020) — attendance figures reported by Fire Marshalls ranged from 6,000 to 7,000 and attendance numbers reported by the re-election campaign reached 12,000 (Murphy and Lauer 2020; Wise 2020). Though the turnout of the event was disappointing politically, the crowd size that did materialize is comparable to that seen at many sporting events - including those held by the Women's National Basketball Association, the National Basketball Association (NBA), and the National Hockey League (NHL) — as well as numerous megachurch services.

However, in some ways, this indoor event was quite different from usual sporting events or church-related gatherings, making the rally a potentially poor bellwether for gauging the dangers of indoor events and reopening policies. The rally was accompanied by numerous media reports suggesting there could be violent clashes between the president's supporters and opponents (Baker and Haberman 2020; Bierman 2020; Cohen 2020; Karni 2020; Murphy 2020b; Singh 2020). The National Guard was deployed to maintain order (Murphy 2020c) and numerous businesses and roads closed (Holloway 2020; Fox23News Staff 2020) in anticipation of the event. Thus, the event was coupled with both a local shutdown of many gathering places,

\footnotetext{
${ }^{3}$ There are studies demonstrating spread of COVID-19 at indoor events utilizing contact tracing, however it is difficult to discern what the counterfactual level of transmission would have been (Nishiura et al. 2020; James et al. 2020). Work by Dave et al. (2020d) studies the Black Lives Matter protests (large outdoor events) and estimates a population level effect which includes avoidance behavior by non-attendees.
} 
including restaurants and bars, as well signals to deter non-attendees from visiting the area near the event. These factors may have plausibly generated avoidance behavior in the non-attending population, which could have important offsetting effects on population level growth of COVID19 cases, a point discussed recently in the context of Black Lives Matter protests (Dave et al. $(2020 d) .^{4}$

In the days and weeks following the campaign event, numerous high-profile media reports anecdotally linked the Trump rally to a surge in new COVID-19 cases in Tulsa, drawing on notable attendees or Oklahomans who had tested positive or drawing on post-rally infection trends in the city. ${ }^{5}$ This study is the first to rigorously explore the impact of President Trump's 2020 presidential campaign kickoff rally on social distancing and COVID-19 related outcomes. To begin, we utilize anonymized smartphone data from SafeGraph Inc. to examine the impact of the Tulsa rally on travel into the census block groups (CBGs) where the Tulsa rally took place. We document that the Tulsa event increased total cell phone "pings" in the treatment CBGs by 22.4 percent and the number of non-resident cell phone pings by 25.7 percent. However, using synthetic control methods, we find that net stay-at-home behavior in Tulsa county, which drew over half of rally attendees (according to cell phone data), did not change, consistent with avoidance behavior of other residents. Such individuals may have chosen to increase stay-athome behavior to avoid congestion at the rally, owing to road and business closures, or in response to predictions of violent clashes between protesters and rally attendees which precipitated the National Guard being called out on June 19 and 20.

\footnotetext{
${ }^{4}$ Attendees of the rally were also drawn from a part of the political distribution that have been found to be less responsive to public health policies aimed at mitigation, which could exacerbate the spread of COVID-19 (Painter and Qiu 2020).

${ }^{5}$ See for instance: Associated Press News (2020); Itkowitz (2020); Murphy (2020e); Jones and Ries (2020); Astor and Weiland (2020); Carlisle (2020); Oprysko (2020).
} 
Then, turning to data from the Centers for Disease Control and Prevention (CDC), we explore whether the Trump rally ignited COVID-19 growth, examining (i) Tulsa county, (ii) Tulsa county and its border counties, and (iii) the state of Oklahoma. Synthetic control estimates provide no evidence that the Tulsa rally precipitated COVID-19 case or mortality growth in any of these jurisdictions during the five weeks following the event. Moreover, a dose-response difference-in-differences approach, which utilizes SafeGraph data on higher "donor" counties to the rally, find no evidence that COVID-19 cases or mortality grew more quickly in counties that sent more attendees into the rally census block group and who returned home.

These findings have important implications for policymakers considering reopening policies. At first pass, our findings appear to imply that indoor events may not be as dangerous to public health as previously thought, particularly if crowd size is relatively modest, the event is accompanied by substantial publicity surrounding the importance of mitigating behaviors (i.e. mask-wearing), and if indoor attendees have their temperature taken upon entry, as they were at the Trump rally (Murphy 2020d). However, the findings also speak to the importance of offsetting community effects in response to large gatherings. To the extent that the Tulsa event displaced mobility that otherwise would have taken place, such as by reducing gatherings of nonhousehold members at restaurants and bars downtown, such compensatory avoidance behavior may have played a vital dampening role in community spread. Because not all future indoor events are likely to generate such avoidance behavior, reopening policies should not dismiss the possibility of disease spread under different circumstances.

\section{Background}

2.1 COVID-19 and Health Policy Response 
Severe acute respiratory syndrome coronavirus 2 (SARS-CoV-2), the virus that causes COVID-19, primarily transmits from one person to another via droplets expelled from an infected individual — from speaking, breathing, coughing, or sneezing — that are absorbed into the nose, mouth, or eyes of an uninfected individual (Centers for Disease Control and Prevention, 2020b; Fineberg, 2020). To reduce transmission, a variety of public health recommendations and mandates have been issued by the government, including (i) recommendations for frequent handwashing (Centers for Disease Control, 2020b), (ii) mandating mask wearing in public (Angell and Newsom, 2020; Cuomo, 2020), and (iii) policies requiring social distancing, such as shelter-in-place orders, non-essential business closures, school shutdowns, mandates for non-household members to remain six feet apart, and limits on the number of individuals that may gather in a group (Centers for Disease Control and Prevention, 2020b; Angell and Newsom, 2020; Cuomo, 2020; Mervosh et al. 2020). Social distancing among the general population may be particularly important to the extent that infectious individuals are asymptomatic (Bai et al., 2020; Pan et al., 2020; Rothe et al., 2020). There is a growing body of evidence to suggest that public policies mandating social distancing and mask wearing played an important role in fighting the spread of COVID-19 (Courtemanche et al. 2020a, 2020b; Dave et al. 2020a, 2020b, 2020c; Friedson et al. 2020, Sears et al. 2020; Lyu and Wehby 2020).

One of the most common policies designed to enforce social distancing is the prohibition of large indoor gatherings, particularly at indoor arenas. By June 1, 2020, nearly all states and the District of Columbia had banned large indoor gatherings such as sporting events and theatre performances (Dave et al. 2020b; Mervosh et al. 2020). Indoor gatherings are viewed as sites with a high potential for that spread of COVID-19 due to airflows, temperatures, and humidity levels that are helpful for virus transmission (Allen and Marr 2020; Contini and Costabile 2020; 
Mittal et al. 2020; Setti et al. 2020). There have also been high profile reports of larger outbreaks in indoor facilities that maintained operations during state COVID-19 shutdowns, such as prisons and meatpacking plants (Mosk et al. 2020; Schlosser 2020; Williams et al. 2020).

\subsection{President Trump's 2020 Campaign Kickoff Rally}

On June 10, 2020, the president's re-election campaign organization, Donald J. Trump for President, Inc., announced that the president would hold an indoor campaign rally on June 19 at the Bank of Oklahoma (BOK) Center in Tulsa, Oklahoma. The BOK Center has a capacity of approximately 19,000 individuals, and the campaign announced that overflow seating was permissible in the nearby outdoor Tulsa Convention Center (Bierman 2020; Singh 2020; Karni 2020). This event was the first large indoor arena event permitted in the United States since the start of the coronavirus outbreak in March 2020 (Bierman 2020; Singh 2020; Karni 2020).

On June 13, President Trump announced that the campaign rally was postponed one day, to June 20, to avoid coinciding with Juneteenth celebrations of the realized emancipation of enslaved peoples in the United States in $1865 .^{6}$ The date change was also related to concerns regarding potential conflicts between the president's supporters and critics (Baker and Haberman 2020; Cohen 2020).

Despite the change of date, event organizers expected to fill both the BOK Center and the nearby Convention Center, with a total estimated attendance of up to 100,000 (Murphy, 2020a; Murphy and Lauer 2020). Attendees began lining up for the event the night prior and gathered throughout the day (Christopher 2020; Hinton 2020; Sgana 2020). At 3:00 PM local time on June

\footnotetext{
${ }^{6}$ A Juneteenth rally took place in the Greenwood District of the city and included Reverend Al Sharpton as a keynote speaker. The gatherings also attracted a large crowd, numbering in the thousands, were outdoors on the streets and sidewalks, and Rev. Sharpton delivered his address in an open field on the campus of Oklahoma State UniversityTulsa.
} 
20, 2020, the BOK Center opened its doors to attendees. Each attendee had his or her temperature checked and only those with normal temperatures were permitted to enter. While mask-wearing was encouraged by public health officials (Centers for Disease Control 2020b), it was not required, and video footage of the event suggests that social distancing (i.e. six-foot distancing requirements among non-household members) did not occur inside or outside the event center and only a small fraction of attendees wore masks (Christopher 2020; Wise 2020).

The rally itself ran from about 7:00 PM to 10:30 PM and attendance did not reach the BOK Center's capacity. Attendance estimates range from approximately 6,000 to 7,000, according the Fire Marshalls, to over 12,000, from the president's election campaign (Murphy and Lauer 2020a; Wise 2020). ${ }^{7}$

While it was not immediately clear why attendance fell so far below expectations, speculation from the Trump campaign and the national news media suggested that potential attendees' concerns over COVID-19 or, perhaps, fears over violent confrontations with protesters may have induced some Trump supporters to remain at home (Murphy 2020). ${ }^{8}$ Indeed, substantial news coverage leading up to the event included alarming information about infection risk of attendance and potential violent confrontations between passionate admirers and critics of the president (Baker and Haberman, 2020; Bierman, 2020; Cohen, 2020; Karni, 2020; Murphy, 2020; Singh, 2020). The presence of National Guard and local police around the BOK Center during the day prior to and the day of the rally may have reinforced concerns over possible confrontations (Murphy 2020).

\footnotetext{
${ }^{7}$ It is unclear whether protesters directly prevented anyone from entering the BOK Center (Murphy 2020a).

${ }^{8}$ The New York Times reported one possibility of inflated expectations related to an elaborate prank by teenagers part of "TikTok Teens" and "K-Pop Stans" (Lorenz and Frenkel 2020).
} 


\subsection{Comparability to Other Indoor Events}

Though the attendance numbers for the campaign rally were well below the pre-event estimates, the re-election rally's actual size makes it representative of many types of events that could occur once indoor event bans are lifted. For example, many sporting events and concerts also occur in arenas such as the BOK Center in Tulsa, and one may reasonably expect attendance of events at such large venues to fall short of capacity during the COVID-19 pandemic. Prior to its cancellation, the 2019-2020 NBA season had an average attendance of 17,750 people per game (ESPN 2020). The Women's National Basketball Association had an average attendance number of 6,535 during the 2019 season (Broughton 2019). Study of the rally and its aftermath could yield meaningful insights for the public health implications of several of possible classes of indoor events, including those that fall below maximum capacity of the venue either due to demand or due to policy design.

Conditional on transmission probabilities and the number of infected in attendance, the expected number of new cases from this campaign rally may be quite similar to that of a sporting event or concert. Professional sports leagues considering holding matches open to the public are also considering requiring match attendees to wear face masks and possibly socially distance. Therefore, all else equal, the transmission probability for an individual attending this campaign rally would be larger than for a typical sporting event or concert to the extent that masks were not worn at the rally (Christopher 2020; Wise 2020). The rally is thus a plausible upper bound on expected new infections from a similar event, conditional on other factors such as overall attendance, and the number of infected in attendance.

Those who did not attend the event may still have found their likelihood of infection increased as a result. If the event at BOK Center infected many individuals who would not have 
otherwise been infected, then anyone who came into close contact with an attendee had an increased chance of infection. Attendees of the rally are a selected sample, drawn from a part of the population distribution that is on average older and less responsive to public health policies aimed at mitigation, factors which could exacerbate the spread of COVID-19 (Barrios and Hochberg 2020; Painter and Qiu 2020). While it is possible that event attendees, or those who would have otherwise come in contact with them, may take measures to reduce the risk of infections, such as self-quarantining, stringently avoiding others, or wearing a mask, because most rally attendees did not wear masks or practice social distancing in the venue (Christopher, 2020; Wise, 2020), it does not seem likely they would voluntarily take-on precautionary measures in other circumstances.

Finally, it is important to note the Tulsa campaign rally differs from other indoor events in regards to potential avoidance behavior on the part of non-attendees. Several businesses, city buildings, and roads and streets in downtown Tulsa were closed in anticipation of the influx of people attending the event (Holloway 2020; Fox23News Staff 2020). Due to concerns over potential clashes and violence, as a precautionary measure, some businesses in the downtown area and just outside the vicinity were boarded up (Hutchins 2020; Morgan 2020). Soldiers from the Oklahoma Army National Guard were activated to help provide security in the event of such clashes. These considerations may have increased stay-at-home behaviors among residents who were not planning on attending the campaign rally, and displaced inflows of non-residents who otherwise would be coming into the downtown area in the absence of the campaign event and anticipated disruptions. Such avoidance behaviors could mitigate community spread of COVID19 from attendees and non-attendees alike, and would not likely be present at otherwise comparable indoor events. 


\subsection{Other Activities Near Rally Site}

As noted above, the Bank of Oklahoma Center hosted the rally and the convention center was prepared to host an overflow crowd, including those who wished to attend the events while social distancing away from the arena. The areas where these events took place include two census block groups (CBGs), which encompass downtown Tulsa, and with it a variety of businesses and government services. In this downtown area were many restaurants, several hotels (including DoubleTree by Hilton, Hyatt Regency, and Holiday Inn), and a number of churches (i.e., the First Presbyterian Church of Tulsa, the First Baptist Church of Tulsa, and the Episcopal Diocese of Oklahoma). In addition, the site of the Trump rally included the Brady Arts District, which contains the Oklahoma Jazz Hall of Fame, the Woody Guthrie Center, and the nearby Tulsa Performing Arts Center. ${ }^{9}$

There are a variety of government services also provided in the CBGs where the Trump rally took place. These include the Sheriff's office, the county jail, the Tulsa County Courthouse, United States Postal Service, and the Tulsa County Library. Finally, there is the large Oklahoma State University Medical Center. ${ }^{10}$ The downtown areas attract considerable inflows of non-residents on weekends, and below we argue that such inflows would have been expected in the absence of the Trump event.

In anticipation of the Trump rally, a number of businesses and county offices closed, and the city of Tulsa announced closures of a number of roadways in the area. The Tulsa Police Department announced their cooperation with the Secret Service "to provide maximum security

\footnotetext{
${ }^{9}$ The well-known business district, Greenwood is also located nearby.

${ }^{10}$ At the time of this writing, visitors to this hospital are restricted to those requiring end-of-life care, labor and delivery, pre- or post-operative care.
} 
for Trump as the country is in a state of unrest" and "to expect significant restrictions to roads in the downtown Tulsa area...through Saturday [June 20]" (Fox23News Staff 2020). Over 40 local businesses, including many restaurants and bars, announced voluntary closures on the day of the rally, and government officials decided to close several public buildings and their associated services, including the Tulsa County Library and Tulsa County Courthouse (Fox23News Staff 2020). Together, these voluntary and government-issued closures, coupled with media reports of severe congestion, potential for violent clashes, and possibility of COVID-19 "super spread" (King and Rodriguez 2020) raise the possibility of substantial community avoidance behavior in response to the rally.

\section{Data}

\subsection{Anonymized Smartphone Data}

Measures of social distancing are constructed using data available from SafeGraph Inc. ${ }^{11}$ This firm provides census-block-group-level data from 45 million anonymized smartphone devices. These data are useful for measuring stay-at-home behavior and travel away from home, and have been used by the Centers for Disease Control and Prevention to study social distancing behavior during the time of the COVID-19 epidemic in the United States. In addition, researchers analyzing social distancing policies in the United States have also used these data to study the impact of mitigation policies and large outdoor social gatherings on social distancing behaviors (Andersen et al. 2020; Dave et al. 2020a,b,c,d; Friedson et al. 2020; Abouk and Heydari 2020; Lasry et al. 2020). The time period of analysis for social distancing ranges from

\footnotetext{
${ }^{11}$ These data are available at: https://www.safegraph.com/covid-19-data-consortium
} 
June 5, 2020 to June 27, 2020, a period including two weeks leading up to the Tulsa rally and 7 days following the event.

In the Safe Graph data, a person's "home" is defined as the 153-by-153-meter area receiving the largest number of GPS "pings" from 6PM to 7AM. We can measure "movement" in the SafeGraph data when we observe a smartphone appearing outside of its home. We use these data in two key ways. First, we measure the number of non-resident visitors in a given census block group. Non-Resident Ping Rate measures the number of non-resident pings per 1,000 square meters of size of a census block group $(\mathrm{CBG}) .{ }^{12}$ Our particular interest is to measure the non-resident ping rate in the census block groups where the Trump rally took place, that is, the CBG where the Bank of Oklahoma (BOK) Center and the Convention Center are located.

Between Saturday, June 13 and Saturday, June 20, the date of the Trump event, the rate of non-resident pings at the $\mathrm{CBG}$ which housed the BOK increased by 22.4 percent, reflecting a substantial increase in the number of non-residents in this key treatment CBG. ${ }^{13}$ Appendix Figure 1 shows trends in non-resident pings in the treatment CBGs and "control" CBGs in the state of Oklahoma. The intra-week cyclicality in mobility patterns is notable for non-resident inflows into the treated CBGs. Generally, non-resident pings are highest from Monday through Friday, and decline considerably on Saturdays and Sundays, consistent with these CBGs comprising the central downtown business district. However, during the weekend of the Tulsa campaign event, inflows of non-resident pings were substantially lower on that Friday (relative to prior Fridays), reflecting displacement from early business closures and road closures (some

\footnotetext{
${ }^{12}$ Alternately, normalizing by the population of the CBG, as a proxy for its size and economic activity, yields virtually identical results in relative terms.

${ }^{13}$ For the CBG housing the Convention Center, the increase was more than twofold.
} 
of which had commenced Thursday evening), ${ }^{14}$ and expectedly peaked on Saturday, the day of the event.

In addition, we measure Total Ping Rate, the total number of pings per 1,000 square meters. The total number of pings recorded in the BOK Arena CBG increased by 20.6 percent over the period between June 13 and June 20. Coupled with our findings for non-resident pings, this does suggest some degree of displacement of residents in a key treatment CBG in response to the rally. ${ }^{15}$ This could reflect one dimension of avoidance behavior by local residents.

Importantly, we are able to measure the home counties of those non-residents (those who did not record a "home residence" in the CBG) who appeared in the treatment CBGs. ${ }^{16}$ The national map in panel (a) of Figure 1 documents the counties that drew the most residents into the rally. ${ }^{17}$ As shown, the rally was largely an Oklahoma event and, more precisely, a Tulsa county event. About half (43 percent) of the total of non-resident pings in the Trump rally CBGs were recorded from individuals whose homes were recorded in Tulsa county. Another 38 percent of the pings came from other counties in the state of Oklahoma outside of Tulsa county. Finally, 18 percent of pings came from outside of the state of Oklahoma, largely in the border counties of Texas (including Clay and Grayson counties), Missouri (including McDonald and Newton counties), and Arkansas (including Benton and Washington counties). Panels (b) and

\footnotetext{
${ }^{14}$ See Fox23News Staff (2020).

${ }^{15}$ For both treatment CBGs combined, the percent increase in non-resident pings was 52.6 percent, while the total number of pings rose by 46.7 percent, again reflective of displacement.

${ }^{16} \mathrm{We}$ are unable to precisely detect whether residents of the treatment CBG attended the rally.

${ }^{17}$ We define a High Inflow as a county (Tulsa county) that contributed more than 9.5 percent of visitors to the treatment CBGs on June 20, Moderate-High Inflow as a county contributing 2.9 to 9.4 percent of visitors, ModerateLow Inflow as a county contributing 1 to 2.8 percent of visitors, and Low Inflow as a county contributing 0.1 to 1 percent of visitors.
} 
(c) of Figure 1 further isolate the state of Oklahoma and Oklahoma along with its border states to highlight jurisdictions that drew the most residents to the rally. ${ }^{18}$

Second, we use four measures of net social distancing behavior at the county-level.

These include Median Hours at Home, which measures the median number of hours respondents spend at their home (mean for Oklahoma = 11.5 and mean for Tulsa County $=11.7$ ), Mean Hours at Home, which captures the mean of the same measure (mean for Oklahoma $=11.3$ and mean for Tulsa County $=11.5)$, Percent of Time at Home, which measures the percent of total time that the phone was turned on that was pinged at home (mean for Oklahoma $=78.8$ percent and mean for Tulsa County $=81.6$ percent), and Percent at Home-Full Time, which measures the mean percent of individuals who spent the full day at home (mean for Oklahoma $=24.3$ percent and mean for Tulsa County $=26.7$ percent $)$.

\subsection{COVID-19 Cases and Deaths}

We measure county-level COVID-19 cases and deaths using state- and county-level data provided by the Centers for Disease Control and Prevention (CDC), and made available via the Kaiser Family Foundation and the New York Times. ${ }^{19}$ Our COVID-19 case analysis is conducted over the period from June 6, 2020 through July 24, 2020. During this period, the mean COVID19 case rate per 100,000 population in the state of Oklahoma was 382.6 and the death rate was 10.0. For Tulsa county, the mean case (mortality) rate was 554.2 (10.9) per 100,000 population. Finally, an examination of Tulsa county and its border counties (Creek, Okmulgee, Osage,

\footnotetext{
${ }^{18}$ For comparison, Appendix Figures 2A and 2B show jurisdictions with pings in treatment CBGs for June 6 and June 13, each of which are Saturdays.

${ }^{19}$ These data are available at: https://github.com/nytimes/covid-19-data
} 
Pawnee, Rogers, Wagoner, and Washington counties) revealed a mean COVID-19 case (mortality) rate of $478.6(14.5)$ per 100,000 population.

In Appendix Figure 3A, we show trends in COVID-19 cases in the state of Oklahoma, in Tulsa county, and in Tulsa county and its surrounding border counties ("Tulsa county Cluster"). We document that though Tulsa county starts off at a similar rate of COVID-19 cases as the state of Oklahoma, the rate of COVID-19 growth is faster in Tulsa county. By July 24, there were nearly 400 more COVID-19 cases per 100,000 in Tulsa county as compared to the state of Oklahoma. In Appendix Figure 3B, we examine COVID-19-related mortality. We find that the death rate is low in Tulsa county as compared to its surrounding border counties. Similar to cases, we document that Tulsa county has a similar rate of COVID-19 death growth as the state of Oklahoma at the start, but then experiences faster growth over the latter part of the sample period.

\section{Empirical Approach}

\subsection{Non-Resident Travel}

We begin by estimating the effect of the Trump rally on non-resident and total pings in the CBGs where Trump rally events were organized (the BOK Center and the adjacent Convention Center). We pool a panel of 2,965 CBGs in the state of Oklahoma across 22 days and estimate a difference-in-differences model of the following form:

Non-Resident Ping Rate gct $=\beta_{0}+\beta_{1}$ Trump $_{\mathrm{gt}}+\beta_{2}$ Temp $_{\mathrm{ct}}+\beta_{3}$ Precip $_{\mathrm{ct}}+\beta_{4} B L M_{\mathrm{ct}}+\alpha_{\mathrm{g}}+\tau_{\mathrm{t}}+\varepsilon_{\mathrm{gct}}$ 
Here Non-Resident Ping Rate gct $_{\text {is }}$ is the non-resident GPS ping rate in census block group $g$ in county $c$ on day $t$, Trump $p_{\mathrm{gt}}$ is the interaction of an indicator for June $20^{\text {th }}$ and whether the CBG is one of the two in which primary Trump rally events took place, Temp $p_{\mathrm{ct}}$ is a measure of the average temperature (in degrees Celsius) in county $c$ on day $t$, Precip $p_{\mathrm{ct}}$ is a dichotomous variable capturing whether measurable precipitation fell that day, ${ }^{20}$ and $B L M_{\mathrm{ct}}$ is a county-level indicator for whether a Black Lives Matter (BLM) protest took place in a metropolitan area with a municipal population greater than $100,000 .{ }^{21}$ Finally, $\alpha_{\mathrm{g}}$ is a time-invariant census block group effect and $\tau_{\mathrm{t}}$ is a CBG-invariant day effect that captures intra-day cyclicality in travel behavior in addition to secular trends. All regressions are weighted by the census block group population.

Following Buchmueller et al. (2011) and Cunningham and Shah (2018), statistical inference is conducted by re-estimating $\beta_{1}$ from equation (1) $G-2$ times for each untreated census block group. We then compare the main estimate to the distribution of placebo estimates by ranking them. If the estimate of the true treatment effect is in the top 5 percent of all (treatment plus placebo) estimates, then we judge it statistically distinguishable from zero at the 5 percent level.

Our estimate of $\beta_{1}$ will be unbiased only if the common trends assumption is satisfied. We take a number of tacks to ensure that will be true. First, our analysis takes place entirely within Oklahoma, where major policy changes regarding reopening were conducted at the statelevel and hence are captured by the common day fixed effect. Second, we explore the robustness of our findings to including county-specific linear time trends, to capture unmeasured time shocks that could be correlated with social distancing and the Trump event. Finally, we also

\footnotetext{
${ }^{20}$ Weather data are available at: https://www.ncdc.noaa.gov.

${ }^{21}$ These data are described in Dave et al. (2020d).
} 
utilize event study analyses, which capture social distancing trends in the weeks leading up to the Trump event.

\subsection{COVID-19 Cases and Mortality}

The previous analyses on the scale of non-resident travel, in conjunction with the inflow patterns across counties that contributed the largest numbers of rally attendees, highlight areas of focus for studying potential effects on COVID-19 cases as attendees travel back home. In order to evaluate the impact of the Trump rally on COVID-19 cases and mortality, we first turn to a synthetic control approach (Abadie et al. 2010). This approach has been used by several recent studies exploring how COVID-19 mitigation policies have affected coronavirus spread (Friedson et al 2020; Dave et al. 2020c). Motivated by findings in Figure 1, we begin by examining three treatment jurisdictions: (i) Tulsa county, the county that included the rally, (ii) Tulsa county and its surrounding border counties (“Tulsa cluster”), and (iii) the state of Oklahoma.

We use several approaches to generate our synthetic treatment units to ensure that our estimates are not influenced by researcher-driven matching characteristics. First, in all cases, we exclude border states from the donor pool given that some border counties of these states contributed travelers to the Trump rally (see Figure 1). In addition, for our Tulsa county-based analysis, we (i) exclude other counties within the state of Oklahoma as potential donors, (ii) exclude donor counties that contributed positive number of cell phone pings in the treatment CBGs on June 20, and (iii) focus on donor counties (and their border counties) with urbanization that approximates Tulsa county. Specifically, we restrict the donor pool to counties with urbanicity rates between 93 percent and 98 percent, a band that narrowly envelopes Tulsa county's urbanicity of 95.2 percent, or counties with population-weighted density similar to 
Tulsa county. ${ }^{22}$ Population-weighted density captures the density where the average person lives; based on this measure, Tulsa has a weighted population density of 3,250 per square mile, and we restrict the donor pool to a band of $+/-1,000$ enveloping Tulsa. ${ }^{23}$ Given the vital role of social interactions and crowding in contributing to community spread of the coronavirus, drawing on a donor pool of urbanized, densely populated counties similar to Tulsa improves the quality of synthetic counterfactual. ${ }^{24}$

Second, to ensure that the synthetic control was similar to the treatment jurisdiction on pre-rally COVID-19 cases and mortality, we match on (i) cumulative COVID-19 cases on each day for the two weeks prior to the rally (June 5, 2020 to July 18, 2020, allowing June 19, a travel day for some arriving in Tulsa, to have different COVID-19 case levels), or (ii) cumulative COVID-19 cases on six pre-rally days (June 6, June 8, June 10, June 14, June 16 and June 18) when we choose to match on other observable characteristics of jurisdictions that may influence COVID-19 case or mortality growth.

We focus on several observable traits that have been found to influence COVID-19 case growth in the selection of our synthetic control, including median hours spent at home during the pre-rally period (11.6 hours in Oklahoma and 11.4 hours in Tulsa County), COVID-19 testing rate per 100,000 population (6841.6 per 100,000 in the state of Oklahoma), state reopening policies (number of days that the state has permitted reopening of restaurants/bars, retail,

\footnotetext{
${ }^{22}$ Urbanicity rates are the proportion of individuals living in an urban area instead of a rural area, calculated using 2010 Census data available from https://www.census.gov/data/datasets/2010/dec/stateside-pums.html. The state of Oklahoma has an urbanicity rate of 66.2 percent.

${ }^{23}$ We compute the weighted population density for each county by combining population density at the census block group level weighted by the population of each CBG. See: https://www.census.gov/programs-surveys/metromicro/data/tools/metro-micro-help/variables.html.

${ }^{24}$ Widening this constraint to include donor counties with urbanicity rates greater than 90 percent does not materially alter our results.
} 
personal care services and gyms and entertainment $)^{25}$, and whether the state issued a maskwearing mandate.

We estimate the unobserved counterfactual COVID-19 case or mortality rate for Tulsa county, the Tulsa cluster (Tulsa County and its border counties), or the state of Oklahoma on pretreatment day $t$ by $\sum_{j} w_{j} * \operatorname{COVID} D_{j t}$, where $w_{j}$ is the weight assigned to donor jurisdiction $j$. The estimated weights $w_{j}$ are chosen to minimize the absolute difference between $C O V I D_{i=T u l s a, t}$ and $\sum_{j} w_{j} * \operatorname{COVID} D_{j t}$ and for all pre-treatment days. Then, the per-day treatment effect $\alpha_{\mathrm{t}}$ is estimated as $\alpha_{t}=\operatorname{COVID} D_{i=\text { Tulsa }, t}-\sum_{j} w_{j} *$ COVID $D_{j t}$ for $\mathrm{t} \in\left[\right.$ June $20^{26}$, July 24]. The average treatment effect is then the average over the post-treatment window.

In addition to the above COVID-19 analysis, we also use the above synthetic control methods for examining net stay-at-home behavior in Tulsa county and the Tulsa cluster using the four stay-at-home measures described above. This analysis is motivated by recent work showing that increased social mobility to attend an event may be countered by behavior of non-attendees who may choose to avoid congestion or due to fear of violence from political clashes (Dave et al. 2020d).

The above analyses focused on Tulsa county and its surrounding areas since the campaign rally was largely a greater Tulsa event, with the Tulsa cluster supplying the majority (57.2 percent) of attendees. Nevertheless, rally-goers from other parts of the state (notably counties comprising Oklahoma City), and to a smaller extent from other states, were also observed in the treated CBGs on the day of the campaign event. We therefore also broaden our focus to outside the greater Tulsa area, in order to assess whether there were any discernible

\footnotetext{
${ }^{25}$ Hence, if the state rolls back its reopening or suspends it for any or all of these sectors, this will be reflected in the separate duration measure of days for each sector that the state has remained reopened over the sample period.

${ }^{26}$ In our main specification, we also include June 19 as a posttreatment day given travel to the event that day. Using June 20 as the first post-treatment day yields a qualitatively similar pattern of results.
} 
changes in COVID-19 cases or mortality in these other areas that contributed attendees at the rally. Specifically, we explore a dose-response difference-in-differences model by taking advantage of the variation in non-resident pings to the treatment CBGs, as shown in Figure 1. That is, we pool a panel of counties and days from Oklahoma and its bordering states (Arkansas, Colorado, Kansas, Missouri, New Mexico, and Texas) and estimate the following specification:

$\log (\text { COVID-19 })_{\mathrm{cst}}=\beta_{0}+$ Inflow $_{\mathrm{c}} *$ PostRally $_{\mathrm{t}} * \boldsymbol{\beta}_{\mathbf{1}}+\mathbf{X}_{\mathrm{st}} * \boldsymbol{\beta}_{\mathbf{2}}+\mathbf{Z}_{\mathrm{ct}} * \boldsymbol{\beta}_{\mathbf{3}}+\alpha_{\mathrm{c}}+\tau_{\mathrm{t}}+\alpha_{\mathrm{c}} * \mathrm{t}+\mu_{\mathrm{cst}}$

where Inflow is a vector measuring inflows of home counties that contributed to non-resident pings in the treatment CBGs on the day of the Trump rally, June 20, (High Inflow, ModerateHigh Inflow, Moderate-Low Inflow, Low Inflow) as measured by SafeGraph using data on smartphone home locations and destinations (see Figure 1 and footnote 16). For COVID-19 confirmed cases, we utilize a log transformation, while for deaths, we utilize an inverse hyperbolic sine transformation. The latter approximates the natural log, is interpreted in a similar manner, but has the advantage of retaining areas with zero death counts (Bellemare and Wichman 2020). ${ }^{27}$

In alternate specifications, we also define relative inflow measures that account for the population of the county that contributed residents to the treatment $\mathrm{CBG}$, in order to capture heterogeneity arising from differential risk of exposure from potential population mixing. ${ }^{28}$ For

\footnotetext{
${ }^{27}$ Approximately 44 percent of county-day observations had zero death counts, mainly representing rural counties. Our estimates are not sensitive to utilizing a log transformation, and dropping these county-days with zero deaths, or utilizing a log transformation after adding one to the death count in all counties.

${ }^{28}$ Based on the relative share measure, we define high inflow as a county that contributed more than 10 percent of its observed residents (as measured by resident pings) to the treatment CBGs on June 20, moderate-high inflow as a county contributing 6 to 10 percent of its observed residents, moderate- low inflow as a county contributing 1 to 6 percent of its residents, and low inflow as a county contributing 0.1 to 1 percent of its residents. See Appendix Figure 4 for a map of counties in Oklahoma that drew the most residents to the rally, based on the relative share of the home county population.
} 
instance, 100 returning residents from the rally to their home county would have different implications for community spread if the home county has a relatively smaller population (than if the home county was more populated). On the one hand, this implies a larger share of the county's population being potentially treated by attending the rally; on the other hand, interactions between the returning attendees and non-attendees may be more limited if the home county is relatively sparsely populated, ceteris paribus.

Turning back to equation (2), PostRally $\mathbf{y}_{\mathrm{t}}$ measures post-Trump rally windows capturing the incubation period (up to 5 days following the rally), the aftermath of the incubation period (6-14 days), 15-29 days, and 30-34 days after the rally. This post-treatment window (up to 34 days after treatment) captures a period well after the median incubation period for COVID-19 (5.1 days) and exceeds the time after which 97 percent of infected individuals would have exhibited symptoms ( $\mathrm{Li}$ et al. 2020). In addition, $\boldsymbol{X}_{\boldsymbol{s} \boldsymbol{t}}$ is a vector of state characteristics including separate indicators of state reopening policies for each of the following sectors including restaurants/bars, retail, personal care services, and gyms and entertainment activity, the presence of a state shelter-in-place order (SIPO), the COVID-19 testing rate per 100,000 population, and whether the state had issued a mask-wearing mandate; and $\mathbf{Z}_{\mathrm{ct}}$ is a vector for the average temperature in the county, whether measurable precipitation fell in the county, and the onset of Black Lives Matter protests in major urban centers in the county (Dave et al. 2020d). In addition, we include a set of county fixed effects, $\alpha_{c}$, day fixed effects, $\tau_{t}$, and a county-specific linear time trend $\left(\alpha_{c} * t\right)$. This last control may account for differential growth trends of COVID- 
19 across states and counties. ${ }^{29}$ To evaluate the common trends assumption, we conduct eventstudy analyses for counties that contributed large shares of residents to the Trump rally CBGs. ${ }^{30}$

\section{Results}

Our difference-in-differences estimates of the effect of the indoor political rally on nonresident travel are reported in Table 1; the corresponding event-study analysis is shown in Figure 2. Our main findings on COVID-19 are shown in Figures 3-7 and Tables 2-5.

\subsection{Non-Resident Travel and Social Distancing}

We first assess the effects of the Tulsa rally on the scope of non-resident travel behavior into the census block groups containing the planned venues, based on equation (1). Estimated effects of the rally on the non-resident ping rate (Panel I) and the total ping rate (Panel II) in the treatment CBGs are shown in Table 1. Column (1) includes day and CBG fixed effects, column (2) adds controls for temperature and weather, column (3) adds controls for the onset of Black Lives Matter protests in large cities in the county (see Dave et al. 2020d), and column (4) adds controls for county-specific linear time trends. While our preferred estimates are from the saturated models that include predictors of social distancing and trend controls, it is reassuring that the estimates are robust across all of these specifications.

\footnotetext{
${ }^{29}$ One concern with the inclusion of a control for a county-specific linear time trend is that its inclusion may bias estimated treatment effects downward in the presence of dynamic impacts (Goodman-Bacon 2018; Dave et al. 2020a). We experiment with alternate specifications, including difference-in-differences models that (i) excluded a county-specific time trend or (ii) included a treatment county-specific linear pre-treatment trend. Event study analyses of these specifications provided no evidence that the Tulsa rally increased COVID-19 cases in counties that drew larger numbers of residents to the June 20 events. Moreover, an examination of pre-treatment trends across each of our specifications suggested that models including county-specific linear time trends produced findings most consistent with the common trends assumption.

${ }^{30}$ Statistical inference is conducted via permutation-based placebo tests in which the estimate of $\beta 1$ from equation (2) is compared to the distribution of $\beta_{1}$ generated from randomly assigning treatment to counties that did not contribute inflows to the Tulsa event.
} 
Estimates in Panel I indicate that the Trump campaign event resulted in a significant increase in non-residents traveling into the treated CBGs, reflecting an increase of 0.10 additional non-resident pings (per 1,000 meters squared). While actual turnout at the rally was far lower than anticipated, the influx on Saturday still amounts to a 25.7 percent increase over inflows into the area that would normally occur on average prior to the rally. Panel II presents commensurate estimates based on total pings (resident and non-resident) observed in the CBGs. As evident from the means, virtually all (92 percent) of the total pings observed in the treated CBGs are from non-residents; this reflects the fact that the CBGs containing the BOK Center and the Convention Center comprise the central business districts of Tulsa and are primarily nonresidential. Hence, it is not surprising that we find highly similar estimates of the rally-induced inflows in Panel II, reflecting an increase in the total ping rate of 0.09 or 22.4 percent relative to the pre-treatment mean. This is virtually identical to the unadjusted difference in inflows between the Saturday of the rally (June 20) and the previous Saturday (June 13) (see Appendix Figure 1).

Figure 2 visually presents the event study analyses for non-resident and total pings observed in the treated CBGs. They underscore the dynamics in travel behavior surrounding the campaign rally. First, inflows into the treated and non-treated CBGs trend quite similarly prior to the event. Second, there is a substantial and significant spike in pings, reflecting an influx of non-residents into the area, on the day of the rally, relative to the control groups. Third, immediately following the event, the treated CBGs experience a commensurate and equally rapid decrease in non-resident pings, consistent with rally-goers returning home, with inflows thereafter reverting to baseline. 
While the estimates in Table 1 reveal an increase in inflows into the treated CBGs of 22 to 26 percent, it is important to note that this is a net increase above and over what would have occurred on a typical Saturday in the absence of the rally. As noted earlier, individuals who otherwise would have visited downtown Tulsa on the weekend may have reduced their travel behavior due to business and road closures, anticipated crowding, and/or safety concerns arising from potential clashes between protesters and rally attendees. Thus, not only did the Trump campaign rally lead to an increase in the level of inflows but would also be expected to shift the composition of visitors into the treated CBGs, as rally attendees displace typical Saturday visitors and their activities.

Such displacement and avoidance behaviors are somewhat more evident in Appendix Figures 5 and 6, when we turn to stay-at-home measures of social distancing. Here we present trends in the extensive and intensive measures of staying at home (Panels a through d) for the larger Tulsa county cluster (Appendix Figure 5) and for just Tulsa county (Appendix Figure 6) along with their respective synthetically-generated counterfactuals. The synthetic controls, constructed through matches on outcomes in all pre-treatment periods, track Tulsa lock-step in all periods prior to the rally. For both the broader Tulsa cluster and just Tulsa county, there is a short-term increase in the percent of residents staying at home full-time (Panel a), on the day of the rally and the preceding Friday, relative to the control group. These effects are statistically significant (two-tailed permutation-based p-value $=0.029$ ). Given that the greater Tulsa area is responsible for the majority of visitors into the treated CBGs for the Trump rally, the increase in the percent of residents staying at home full-time reflects counteracting compensatory behavior on the part of residents who chose not to the attend the rally or leave their homes. That this is consistent with a rally-induced displacement is supported by the short-term duration of the 
increase in stay-at-home behaviors over that Friday and Saturday, and a rapid return to their baseline trends thereafter. Turning to the intensive measures of time spent at home (Panels $\mathrm{c}$ through d), we find no significant or substantial change. Given that attendees from Tulsa and surrounding counties are known to have travelled to the treatment CBGs, thereby reducing their time spent at home, a null effect at this margin also implies countering increase in the time spent at home among other non-traveling sub-populations. ${ }^{31}$

\subsection{COVID-19 Results}

In light of the evidence from Table 1 and the mobility patterns documented in Figure 1, it is clear that, while attendance at the Trump campaign event fell short of expectations, the event nevertheless did attract a significant inflow of visitors into the treated CBGs. Moreover, the visitors primarily hailed from instate (81.6 percent) and mainly from Tulsa county (43.4 percent) and the broader Tulsa cluster (57.2 percent). In assessing the impact of the large indoor gathering on COVID-19 case rates, as attendees returned home, we therefore aim our spotlight on these areas that contributed the largest shares of visitors to the rally.

Figure 3 presents a synthetic control counterfactual evolution of realized COVID-19 cases (Panels a and c) and deaths (Panels b and d) for Tulsa county. Given that Tulsa county is highly urbanized, and the central role played by social interactions and crowding in community spread, we constrain the donor pool to counties that a priori approximate Tulsa in their degree of urbanization as proxied by urbanicity and weighted population density. ${ }^{32}$ We draw on this donor

\footnotetext{
${ }^{31}$ It is more difficult to detect changes in time spent at home at the intensive margin, and thus separate out increases driven by the avoidance behavior of non-attendees from decreases due to attendees traveling to the venue CBGs with these measures of stay-at-home behaviors. Appendix Table 1 presents the point estimates for the synthetic control results on stay-at-home behaviors.

${ }^{32}$ Given differential risk of exposure, population mixing, and other unobservable dynamics in infection spread, it would not be appropriate to include sparsely populated, rural and less urban counties as part of the potential donors.
} 
pool of similar counties, and construct the counterfactual in Panels (a) and (b) by matching on predictors of confirmed infections including social distancing (median hours spent at home) and COVID-19 testing rates and matching on the outcome at six points in time (June 6, 8, 10, 14, 16, and 18) during the pre-treatment period. Panels (c) and (d) further match on states' reopening policies and policies mandating public use of face masks. ${ }^{33}$

These analyses underscore two points. First, despite not forcing matches on the outcome across all pre-treatment days, synthetic Tulsa county trends virtually identically to actual Tulsa county with respect to confirmed cases and deaths prior to the campaign event. Second, there is little indication that the rally had any meaningful effects on confirmed infection rates or mortality rates in Tulsa county relative to the control set, within 35 days of the event. These results provide little support for any sustained or persistent increase in COVID-19 infections, as measured by confirmed cases or deaths in Tulsa county following the campaign event.

Figures 4 and 5 widen the spatial unit of analysis to incorporate the cluster of surrounding counties (Tulsa county and its neighboring counties) and the entire state, respectively. These continue to show no signs of any discernible increase in COVID-19 cases or deaths in Tulsa cluster and the state of Oklahoma, relative to their synthetic controls. ${ }^{34}$

The corresponding point estimates and their permutation-based inferential statistics for our main analyses are reported in Table 2 for confirmed cases. In columns (1) and (2), we match on observable predictors of COVID-19 infection spread in conjunction with cumulative COVID19 cases for a subset of the pre-treatment period (six of the 14 pre-rally days), and in column (3)

\footnotetext{
${ }^{33}$ Appendix Table 2 shows the principal counties (or states, in the case of Oklahoma) that received positive weights from our donor pool in our various matching strategies.

${ }^{34}$ Confirmed cases in the state of Oklahoma are somewhat lower than their respective estimated counterfactuals, though the difference is not statistically significant (Figure 5, Panels a and c). COVID-related mortality rate remained virtually identical between actual and synthetic Oklahoma over the entire 7+ weeks of the analysis period enveloping the rally (Figure 5, Panels $b$ and d).
} 
we match directly on cumulative COVID-19 cases over the entire pre-treatment period. Table 3 reports parallel estimates for COVID-related mortality rates. Estimates in Tables 2 and 3 indicate no consistent or systematic patterns reflective of an increase in COVID-19 cases or deaths following the Tulsa rally, and none of the estimates are statistically distinguishable from zero. It is validating that these results are robust across alternate donor pools, matching algorithms, and variation in the donors and weights used to form the counterfactual set. ${ }^{35}$

Appendix Table 3 presents alternate analyses, following Courtemanche et al. (2020a, b) and Dave et al. (2020c), based on a three-day moving average of growth rate in cases, which is defined as the difference in the natural log of cumulative COVID-19 cases between day $\mathrm{t}$ and day t-1. While growth in cumulative cases tends to be noisier, this measure captures dynamics in new confirmed cases from day to day (that is the rate of change or the derivative of cumulative cases over time) and may magnify effects that might otherwise be masked by looking at changes in total confirmed cases. The synthetic control estimates of the effects of the Trump campaign rally on the growth in cases continue to confirm our prior results, and do not indicate any substantial or significant shift. ${ }^{36}$

\subsection{Dose-Response Results}

\footnotetext{
35 Our main analyses (Figures 3-5 and Tables 2-3) had constrained the donor pool to include jurisdictions with a similar level of urbanization to Tulsa county and to Oklahoma, based on proximity to the treated area's urbanicity rate or weighted population density. Appendix Table 4 presents estimates where we restrict the donor pool alternately based on urbanicity rates alone or weighted population density alone. The results are largely similar. We also generated synthetic control estimates based on the natural log of the outcome (COVID-19 confirmed cases and deaths) in order to assess sensitivity to functional form. Relative changes, that is changes in the log of confirmed cases or deaths, may provide a better counterfactual tracking for Tulsa for infections that are growing at a non-linear exponential rate. These results also do not show any consistent, persistent, or significant increase within five weeks following the campaign event.

${ }^{36}$ Our synthetic approach matches on COVID-19 case growth on each pretreatment day until June 19, and June 19 is included as part of the three-day moving average.
} 
While the Trump campaign rally was largely a Tulsa event drawing almost half of its attending audience from within the county, it did also pull some - though notably a smaller share - of its attendees from more distant parts, including Oklahoma City (more than 100 miles from Tulsa) and from bordering states (see Figure 1). Next, we therefore assess whether the Tulsa event led to any increase in COVID-19 cases across any of the counties that contributed attendees, nearby or far, from within the state or from its neighbors. We exploit variation in nonresident pings into the treated CBGs to assess whether there are any changes in confirmed cases across counties that contributed fewer as compared to more visitors to the rally, and if so, whether effects are larger for home counties that supplied more attendees.

Table 4 reports these county-level dose-response difference-in-differences estimates of the association between pings in the rally CBGs and COVID-19 case counts, based on equation (2). We group counties whose resident cell phones were detected in the treated CBGs on the day of the rally into four categories (Low Inflow; Moderate-Low Inflow, Moderate-High Inflow, High Inflow) that monotonically capture the absolute share of visitors in the treated CBG from the source county. For instance, for the High Inflow county (Tulsa county), more than 9.5 percent of observed visitors in the venue CBGs came from this county, compared to the Low Inflow counties, where less than one percent of visitors traveled from any of these counties. These estimates are reported in the first two columns, which alternately exclude and include extended controls. Counties with low inflows saw slight decreases in infections following the rally ( 6.8 percent 15-29 days after and 7.0 percent 30 or more days after) in the saturated model (column 2). Point estimates for counties with high inflows indicate a 1.6 percent increase within 15-29 
days, and an 8.3 percent decrease 30 or more days after. ${ }^{37}$ None of these estimates are statistically significant or show any consistent patterns reflective of any substantial increase in confirmed cases following the campaign event. That is, we do not find stronger positive effects on cases in counties that drew relatively more attendees to the treated CBGs, especially at the end of three weeks following the event.

Arguably, it is not just the number of visitors returning back to their home county, but also the resident population of the home county, that together may impact the dynamics of population mixing and community transmission. In columns (3) and (4), we report doseresponse estimates based on an alternate relative measure of inflow, which considers the share of residents traveling to the rally CBGs relative to the population of the home county, as measured by home resident pings in the Safegraph data. If there are any increases in COVID-19 cases, they would be expected for counties with the most residents pinging in the rally CBGs. Regardless of how we define the inflows, we do not find this to be the case, and estimates continue to suggest no significant changes across the high inflow counties or across any of the other county groupings from which residents visited the treatment CBGs on the day of the rally.

Table 5 reports the corollary county-level dose-response difference-in-differences estimates for mortality. As we do not find any significant effects on COVID-19 cases, we would not expect any effects on mortality. Nevertheless, assessing effects on deaths permits an additional validation check; death counts represent an alternate objective measure of COVID-19 infections that bypasses any issues with the measurement of confirmed case counts potentially conflating selection into testing. As with cases, estimates in Table 5 indicate no significant or

\footnotetext{
${ }^{37}$ For convenience of presentation, we present estimates for four lag windows: 0-5 days, 6-14 days, 15-29 days, and 30 or more days. The event study analyses (Figures 6 and 7) present the results for disaggregated post-treatment effects.
} 
systematic increase in deaths across counties that experience the highest inflows of rally attendees. Thus, the weight of the evidence from these analyses suggests that the event has not had any discernible consistent effect on COVID-19 cases or deaths over a post-rally period of five weeks.

Figures 6 and 7 visually present the event study analyses for the sets of counties alternating from low to high inflows, for cases and deaths respectively. Differential trends in confirmed cases and deaths are fairly flat across each of the treated groups and the controls prior to the rally, and there is little evidence of a significant, substantial or persistent increase in cases for any of these treated groups following the rally. ${ }^{38}$

One concern regarding our finding on the lack of any strong effects for COVID-19 cases is that the post-rally sample period might not be sufficiently protracted to detect an increase in transmission rates. While we acknowledge this possibility, we also note that our sample includes 35 days of data in the post-treatment period, 34 days following the day of the campaign event. This combined with the median incubation period for COVID-19 being 5.1 days, with 75 percent of all infected individuals experiencing symptoms within 6.7 days and 97.5 percent within 11.5 days (Li et al. 2020), suggests that our post-event window is long enough to be able capture any substantial increase in confirmed cases — as well as deaths — if there are any meaningful changes. Moreover, prior work has uncovered strong effects of shelter-in-place orders on confirmed cases within ten days following the adoption of the policy (Friedson et al. 2020; Dave et al. 2020 a, b; c; Courtemanche et al. 2020a, b), and other work in economics has detected

\footnotetext{
${ }^{38}$ A weakly positive (though statistically insignificant) differential trend in the case rate for Tulsa county (relative to the control counties) prior to campaign event is evident (Figure 6 Panel d). The event study however shows little indication of a break in this trend or any sustained increase in cases following the event.
} 
secondary spread of COVID-19 from travel due to spring break at a 2-week time horizon (Mangrum and Niekamp 2020).

\section{Conclusions}

The Trump Campaign's Tulsa rally on June 20, 2020 was the largest indoor event in the United States since March 2020. In the weeks following the event, numerous high-profile news outlets, including the Washington Post, Time, CBS News, and CNN linked the Tulsa rally to a spike in COVID-19 case growth. Commenting on Tulsa's COVID-19 case growth in the weeks following June 20, Tulsa Health Department Executive Director Bruce Dart suggested "we just connect the dots" (Astor and Weiland 2020). However, no study has rigorously examined the impact of the Trump rally on COVID-19.

This study is the first to empirically examine the link between this event and changes in confirmed COVID-19 case rates and mortality rates, drawing focus on areas that drew the most attendees to the census block groups containing the rally venues and to which the attendees traveled back home following the event. During the five weeks of our post-treatment period, we do not find any significant or substantial changes in the trajectory of COVID-19 cases in Tulsa county, which was home to the Trump rally, or from counties that drew attendees to the event. While the data do not allow us to pinpoint all of the mechanisms underlying our findings, we hypothesize several possible explanations.

First, the results are consistent with avoidance behaviors among those who did not attend

to the rally. Given the business and road closures along with the anticipation of large crowds and potential for violence, visitors into the venue CBGs likely displaced typical travellers into the area. These visitors who were displaced would likely have engaged in a number of 'risky' COVID-related behaviors in the treatment CBGs, including bar, restaurant, and entertainment- 
related activities. Moreover, deployment of the National Guard, which stood ready to assist with crowd control and security, along with police and Secret Service efforts, likely deterred many individuals from the area. In other words, individuals who otherwise typically would have travelled into the downtown area on the weekend may have chosen to stay home that weekend or travel elsewhere, and their activities were displaced. There is some indication of a net increase in stay-at-home behaviors coinciding with the rally, as many non-attendees opted not to travel to the area or leave their homes. Dave et al. (2020d) find similar effects, specifically a net increase in stay-at-home behaviors, in communities following the onset of Black Lives Matter protests. Such avoidance behaviors on the part of other segments of the population can change the level and composition of population mixing, and may also serve to isolate individuals of varying risk profiles.

Second, mitigating factors specific to the rally may also have played a role. These included temperature checks prior to entry, a crowd size that filled the arena to only about a third of its capacity, and self-protection behaviors (face masks, social distancing) among some of the attendees. Countering these are other considerations; for instance, individuals attending the Trump campaign rally are a selected sample, on average older and less likely to engage in risk mitigation efforts (Barrios and Hochberg 2020). If these individuals are also less likely to get tested, then they may not be reflected in the official case numbers. ${ }^{39}$ However, given that turnout was far lower than anticipated, possibly in response to concerns over COVID-19 risk, individuals who are more risk-averse, or perceived themselves to be at a higher risk of exposure or complications may have opted to bypass the event. Thus, the risk of infection among attendees may not be representative of the population risk.

\footnotetext{
${ }^{39} \mathrm{We}$ also note that it is possible that due to the selected nature of the rally attendees, the activities forgone to attend the rally may have had a similar infection risk.
} 
While our findings suggest that the first large indoor gathering in the United States since the COVID-19 shutdowns was not associated with a significant rise in confirmed cases, the complexities of the potential mechanisms at play may not imply that all indoor gatherings of a similar scale are necessarily low-risk. Our work highlights the fact that large gatherings such as political rallies or Black Lives Matter protests (Dave et al. 2020d), which have the potential for large offsetting community effects through avoidance behaviors, may not generalize to all indoor events. 


\section{References}

Abadie, Alberto, Alexis Diamond, and Jens Hainmueller. 2010. "Synthetic Control Methods for Comparative Case Studies: Estimating the Effect of California's Tobacco Control Program." Journal of the American Statistical Association 105 (490): 493-505.

Abouk, R., Heydari, B., 2020. The Immediate Effect of COVID-19 Policies on Social Distancing Behavior in the United States (SSRN Scholarly Paper No. ID 3571421). Social Science Research Network, Rochester, NY. https://doi.org/10.2139/ssrn.3571421

Allen, J.G., Marr, L.C., 2020. Recognizing and controlling airborne transmission of SARS-CoV2 in indoor environments. Indoor Air 30, 557-558. https://doi.org/10.1111/ina.12697

Andersen, M., Maclean, J.C., Pesko, M.F., Simon, K.I., 2020. Effect of a Federal Paid Sick Leave Mandate on Working and Staying at Home: Evidence from Cellular Device Data (Working Paper No. 27138), Working Paper Series. National Bureau of Economic Research. https://doi.org/10.3386/w27138

Angell, S.Y., Newsom, G., 2020. California Department of Public Health.

Aschburner, Steve. 2020. Coronavirus pandemic causes NBA to suspend season after player tests positive. NBA.com

Associated Press News. 2020. Reporter at Trump's Tulsa rally tests positive for COVID-19. June 26, 2020. https://apnews.com/3b4f69c49231eff5ec7dabfce02e55aa

Astor, M., and Weiland, N. Coronavirus Surge in Tulsa 'More Than Likely' Linked to Trump Rally. July 10, 2020. https://www.nytimes.com/2020/07/08/us/politics/coronavirus-tulsatrump-rally.html

Bai, Y., Yao, L., Wei, T., Tian, F., Jin, D.-Y., Chen, L., Wang, M., 2020. Presumed Asymptomatic Carrier Transmission of COVID-19. JAMA 323, 1406-1407. https://doi.org/10.1001/jama.2020.2565

Baker, P., Haberman, M., 2020. Trump Moves Tulsa Rally Date 'Out of Respect' for Juneteenth. The New York Times.

Barrios, J.M. and Hochberg, Y. (2020). "Risk Perception Through the Lens of Politics in the Time of the COVID-19 Pandemic." NBER Working Paper No. 27008.

Bellemare, M.F. and Wichman, C.J., 2020. Elasticities and the inverse hyperbolic sine transformation. Oxford Bulletin of Economics and Statistics, 82(1), pp.50-61.

Bierman, N., 2020. Trump says he will resume campaign rallies June 19 in Tulsa. Los Angeles Times.

Broughton, D. 2019. WNBA Turnstile Tracker: Attendance Down At End Of Regular Season. Sports Business Daily. 
https://www.sportsbusinessdaily.com/Daily/Issues/2019/09/10/Research-andRatings/WNBA-Turnstile-Tracker.aspx

Botosaru, Irene., \& Bruno Ferman 2019. "On the Role of Covariates in the Synthetic Control Method.” The Econometrics Journal 22(2): 117-130.

Buchmueller, T. C., DiNardo, J., \& Valletta, R. G. 2011. The effect of an employer health insurance mandate on health insurance coverage and the demand for labor: Evidence from hawaii. American Economic Journal: Economic Policy, 3(4), 25-51.

Carlisle, M. 2020. Three Weeks After Trump's Tulsa Rally, Oklahoma Reports Record High COVID-19 Numbers. July 11, 2020. https://time.com/5865890/oklahoma-covid-19-trumptulsa-rally/

Centers for Disease Control and Prevention. 2020a. Considerations for Events and Gatherings. https://www.cdc.gov/coronavirus/2019-ncov/community/large-events/considerations-forevents-gatherings.html

Centers for Disease Control and Prevention, 2020b. Coronavirus Disease 2019 (COVID-19) Prevention \& Treatment [WWW Document]. Centers for Disease Control and Prevention. URL https://www.cdc.gov/coronavirus/2019-ncov/prevent-getting-sick/prevention.html (accessed 6.25.20).

Christopher, T., 2020. Viral Videos Show Teeming Throngs of Maskless Trump Fans Lining Up for Tulsa Rally. Mediaite.

Cohen, L., 2020. Trump moves campaign rally scheduled for Juneteenth after facing backlash. CBS News.

Contini, D., Costabile, F., 2020. Does Air Pollution Influence COVID-19 Outbreaks? Atmosphere 11, 377. https://doi.org/10.3390/atmos11040377

Courtemanche, C., Garuccio, J., Le, A., Pinkston, J., Yelowitz, A., 2020a. Did Social-Distancing Measures in Kentucky Help to Flatten the COVID-19 Curve? 24.

Courtemanche, C., Garuccio, J., Le, A., Pinkston, J., Yelowitz, A., 2020b. Strong Social Distancing Measures In The United States Reduced The COVID-19 Growth Rate. Health Affairs 10.1377/hlthaff.2020.00608. https://doi.org/10.1377/hlthaff.2020.00608

Cunningham, S. and Shah, M., (2018). "Decriminalizing Indoor Prostitution: Implications for Sexual Violence and Public Health.” The Review of Economic Studies, 85(3), pp.16831715.

Cuomo, A., 2020. No. 202.17: Continuing Temporary Suspension and Modification of Laws Relating to the Disaster Emergency.

Dave, D.M., Friedson, A.I., Matsuzawa, K., McNichols, D., Sabia, J.J., 2020a. Did the Wisconsin Supreme Court Restart a COVID-19 Epidemic? Evidence from a Natural 
Experiment (Working Paper No. 27322). National Bureau of Economic Research. https://doi.org/10.3386/w27322

Dave, D.M., Friedson, A.I., Matsuzawa, K., Sabia, J.J., 2020b. When Do Shelter-in-Place Orders Fight COVID-19 Best? Policy Heterogeneity Across States and Adoption Time (Working Paper No. 27091). National Bureau of Economic Research. https://doi.org/10.3386/w27091

Dave, D.M., Friedson, A.I., Matsuzawa, K., Sabia, J.J., Safford, S., 2020c. Were Urban Cowboys Enough to Control COVID-19? Local Shelter-in-Place Orders and Coronavirus Case Growth (Working Paper No. 27229). National Bureau of Economic Research. https://doi.org/10.3386/w27229

Dave, D.M., Friedson, A.I., Matsuzawa, K., Sabia, J.J., Safford, S., 2020d. Black Lives Matter Protests, Social Distancing, and COVID-19 (Working Paper No. 27408), Working Paper Series. National Bureau of Economic Research. https://doi.org/10.3386/w27408

ESPN. 2020. NBA Attendance Report 2020. http://www.espn.com/nba/attendance

Fineberg, H.V., 2020. Rapid Expert Consultation on the Possibility of Bioaerosol Spread of SARS-CoV-2 for the COVID-19 Pandemic. National Academies of Sciences, Engineering, Medicine.

Fox23News Staff., 2020. What to Know: Closures Expected for Trump Rally in Tusla. June 18, 2020. https://www.kjrh.com/news/local-news/closing-some-tulsa-businesses-closingahead-of-rallies-this-weekend

Friedson, A.I., McNichols, D., Sabia, J.J., Dave, D., 2020. Did California's Shelter-in-Place Order Work? Early Coronavirus-Related Public Health Effects (Working Paper No. 26992). National Bureau of Economic Research. https://doi.org/10.3386/w26992

Goodman-Bacon, A., 2018. Difference-in-differences with variation in treatment timing (Working Paper No. w25018). National Bureau of Economic Research. https://doi.org/10.3386/w25018

Gupta, S., Nguyen, T.D., Rojas, F.L., Raman, S., Lee, B., Bento, A., Simon, K.I., Wing, C., 2020. Tracking Public and Private Responses to the COVID-19 Epidemic: Evidence from State and Local Government Actions (Working Paper No. 27027). National Bureau of Economic Research. https://doi.org/10.3386/w27027

Hinton, C., 2020. Early bird Trump supporters want to be among first at rally. Oklahoman.com.

Holloway, J., 2020. Downtown Tulsa Roads Closing in Preparation for Weekend Trump Rally. June 18, 2020. https://www.news9.com/story/5eeb43856aba30686324820d/downtowntulsa-roads-closing-in-preparation-for-weekend-trump-rally-

Hutchins, E., KTUL Staff, 2020. Tulsa businesses continue to board up ahead of large crowds at Trump rally, protests. June 18, 2020. https://ktul.com/news/local/tulsa-businessescontinue-to-board-up-ahead-of-large-crowds-at-trump-rally-protests 
Itkowitz, C. 2020. Herman Cain, who attended Trump's Tulsa rally, hospitalized with covid-19. July 2, 2020. https://www.washingtonpost.com/politics/herman-cain-who-attended-trumpstulsa-rally-hospitalized-with-covid-19/2020/07/02/55daf86e-bc92-11ea-80b940ece9a701dc_story.html

James, A., Eagle, L., Phillips, C., Hedges, D.S., Bodenhamer, C., Brown, R., Wheeler, J.G. and Kirking, H., 2020. High COVID-19 attack rate among attendees at events at a churchArkansas, MMWR. Morbidity and mortality weekly report ; v. 69, early release, May 19, 2020

Jones, K. and Ries, B. 2020. Tulsa sees Covid-19 surge in the wake of Trump's June rally. July 9, 2020. https://www.cnn.com/2020/07/08/us/tulsa-covid-trump-rally-contact-tracerstrnd/index.html

Karni, A., 2020. Trump Will Return to Campaign Trail With Rally in Tulsa. The New York Times.

Lasry, A., Kidder, D., Hast, M., Poovey, J., Sunshine, G., Winglee, K., Zviedrite, N., Ahmed, F., Ethier, K.A., CDC Public Health Law Program, New York City Department of Health and Mental Hygiene, Louisiana Department of Health, Public Health - Seattle \& King County, San Francisco COVID-19 Response Team, Alameda County Public Health Department, San Mateo County Health Department, Marin County Division of Public Health, CDC Public Health Law Program, Clodfelter, C., Howard-Williams, M., Hulkower, R., Jeong, G., Landsman, L., McCord, R., Moreland, A., Shelburne, J., Louisiana Department of Health, Billioux, A., Hand, J., Kanter, J., Smith, A., Sokol, T., Public Health - Seattle \& King County, Duchin, J.S., Fagalde, M.S., Pogosjans, S., Alameda County Public Health Department, Brown, R., Huang, S., Moss, N., Pan, E., Shemsu, M., Yette, E., San Mateo County Health Department, Bock, C., Curtis-Robles, R., Lockett, C., Morrow, S., Sallenave, C., Marin County Division of Public Health, Santora, L., Willis, M., 2020. Timing of Community Mitigation and Changes in Reported COVID-19 and Community Mobility - Four U.S. Metropolitan Areas, February 26-April 1, 2020. MMWR Morb. Mortal. Wkly. Rep. 69, 451-457. https://doi.org/10.15585/mmwr.mm6915e2

Lorenz, T., Browning, K. and Frenkel, S. 2020. TikTok Teens and K-Pop Stans Say They Sank Trump Rally. New York Times. https://www.nytimes.com/2020/06/21/style/tiktok-trumprally-tulsa.html

Lyu, W. and Wehby, G.L., 2020. Community Use Of Face Masks And COVID-19: Evidence From A Natural Experiment Of State Mandates In The US: Study examines impact on COVID-19 growth rates associated with state government mandates requiring face mask use in public. Health Affairs, pp.10-1377.

Mervosh, S., Lu, D., Swales, V., 2020. See Which States and Cities Have Told Residents to Stay at Home. The New York Times.

Mittal, R., Ni, R., Seo, J.-H., 2020. The flow physics of COVID-19. Journal of Fluid Mechanics 894. https://doi.org/10.1017/jfm.2020.330 
Morgan, R., 2020. QuikTrip closing some downtown-area stores temporarily ahead of Trump rally out of concern for employees, June 17, 2020.

https://www.tulsaworld.com/business/quiktrip-closing-some-downtown-area-storestemporarily-ahead-of-trump-rally-out-of-concern-for/article_ed0077ec-5dc6-5557-81299f4665fa6458.html\#1

Mosk, M., Rubin, O., Ebbs, S., Barr, L., 2020. Like 'stationary cruise ships': Prisons, factories emerging as deadly coronavirus transit hubs. ABC News.

Murphy, S. 2020a. Oklahoma governor seeks larger event for Trump's Tulsa rally. The Seattle Times.

Murphy, S., 2020b. Many fear Trump's visit to Tulsa could spark violence. AP NEWS.

Murphy, S., 2020c. Trump supporters, protesters face off outside Oklahoma rally. Boston Herald.

Murphy, S. 2020d. Temperature checks, metal barriers, Trump gear: Crowd readies for Tulsa rally. https://wjla.com/news/nation-world/temperature-barriers-trump-gear-tulsa-rally

Murphy, S. 2020e. Tulsa Health Official Says Trump Rally 'Likely Contributed' to Surge in COVID-19 Cases. July 8, 2020. https://time.com/5864434/tulsa-trump-rally-coronavirussurge/

Murphy, S., Lauer, C., 2020. Tulsa arena hosts thousands for Trump rally amid virus fears. AP NEWS.

Nishiura, H., Oshitani, H., Kobayashi, T., Saito, T., Sunagawa, T., Matsui, T., Wakita, T., COVID, M. and Suzuki, M., 2020. Closed environments facilitate secondary transmission of coronavirus disease 2019 (COVID-19). medRxiv.

Oprysko, C. 2020. Oklahoma governor tests positive for coronavirus after hosting Trump rally. July 15, 2020. https://www.politico.com/news/2020/07/15/oklahoma-governor-positivefor-coronavirus-363951

Painter, M., \& Qiu, T. 2020. Political beliefs affect compliance with covid-19 social distancing orders. (SSRN Scholarly Paper No. ID 3569098.). Social Science Research Network, Rochester, NY. https://papers.ssrn.com/sol3/papers.cfm?abstract_id=3569098

Pan, X., Chen, D., Xia, Y., Wu, X., Li, T., Ou, X., Zhou, L., Liu, J., 2020. Asymptomatic cases in a family cluster with SARS-CoV-2 infection. Lancet Infect Dis 20, 410-411. https://doi.org/10.1016/S1473-3099(20)30114-6

Rothe, C., Schunk, M., Sothmann, P., Bretzel, G., Froeschl, G., Wallrauch, C., Zimmer, T., Thiel, V., Janke, C., Guggemos, W., Seilmaier, M., Drosten, C., Vollmar, P., Zwirglmaier, K., Zange, S., Wölfel, R., Hoelscher, M., 2020. Transmission of 2019-nCoV Infection from an Asymptomatic Contact in Germany. New England Journal of Medicine 382, 970971. https://doi.org/10.1056/NEJMc2001468 
Schlosser, E., 2020. America's Slaughterhouses Aren’t Just Killing Animals. The Atlantic.

Sears, James and Villas-Boas, J. Miguel and Villas-Boas, Vasco and Villas-Boas, Sofia, Are We \#Staying Home to Flatten the Curve? (May 25, 2020). Department of Agricultural and Resource Economics. CUDARE Working Papers. Available at SSRN: https://ssrn.com/abstract=3569791.

Setti, L., Passarini, F., De Gennaro, G., Barbieri, P., Perrone, M.G., Borelli, M., Palmisani, J., Di Gilio, A., Piscitelli, P., Miani, A., 2020. Airborne Transmission Route of COVID-19: Why 2 Meters/6 Feet of Inter-Personal Distance Could Not Be Enough. International Journal of Environmental Research and Public Health 17, 2932. https://doi.org/10.3390/ijerph17082932

Sgana, N., 2020. Trump supporters camp out in line overnight for his rally in Tulsa.

Singh, M., 2020. Donald Trump to hold rally in Oklahoma, first since coronavirus pandemic began. The Guardian.

Treisman, R. 2020. Midwest: Coronavirus-Related Restrictions By State. NPR. https://www.npr.org/2020/06/11/847413697/midwest-coronavirus-related-restrictions-by$\underline{\text { state }}$

Williams, T., Seline, L., Griesbach, R., 2020. Coronavirus Cases Rise Sharply in Prisons Even as They Plateau Nationwide. The New York Times.

Wise, J., 2020. Tulsa Fire Department says Trump rally attendance was about 6,200. TheHill.

World Health Organization, 2020. Q\&A: Influenza and COVID-19 - similarities and differences [WWW Document]. URL https://www.who.int/news-room/q-a-detail/q-a-similarities-anddifferences-covid-19-and-influenza (accessed 6.24.20) 
Figure 1. Distribution of Home Counties for Absolute Inflows to Treatment Census Block Groups (CBGs) on June 20, 2020

Panel (a): Distribution of Home Counties of Those Who Traveled to Trump Event CBGs

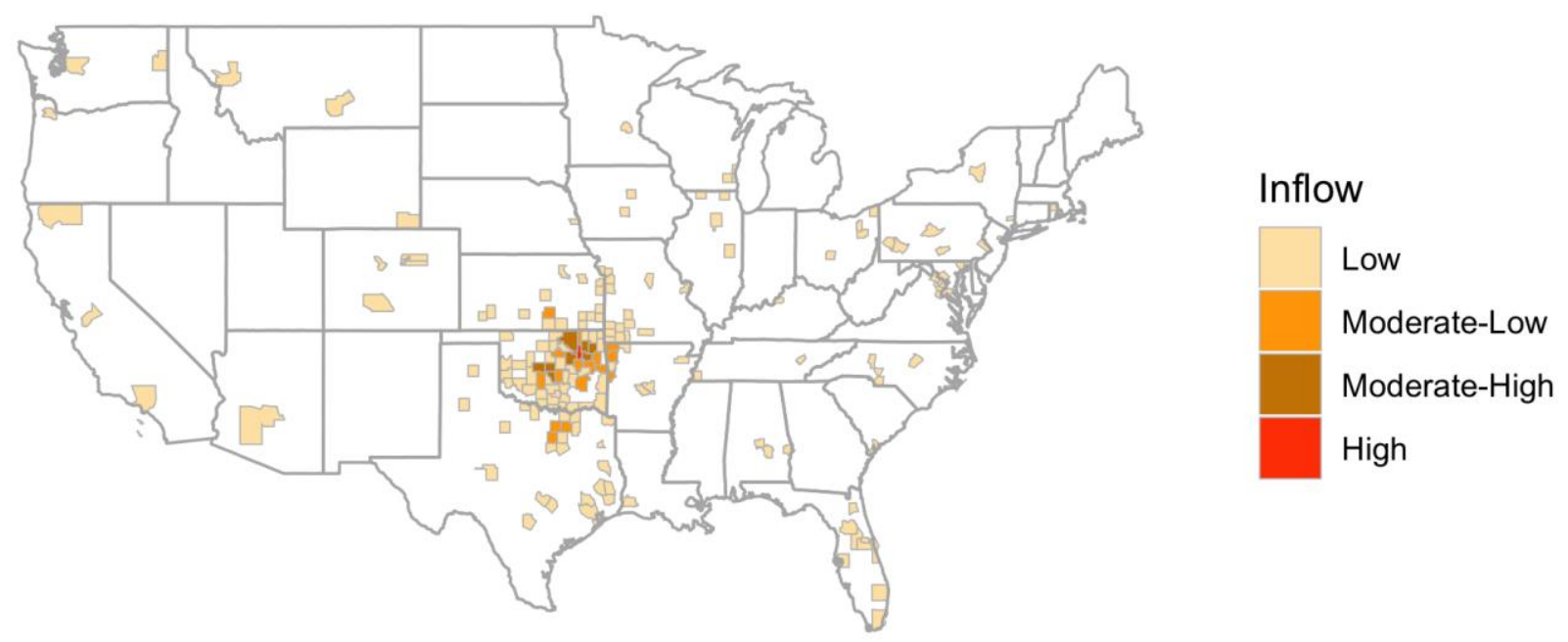

Panel (b): Distribution of Home Counties of Oklahomans Who Traveled to Trump Event CBGs

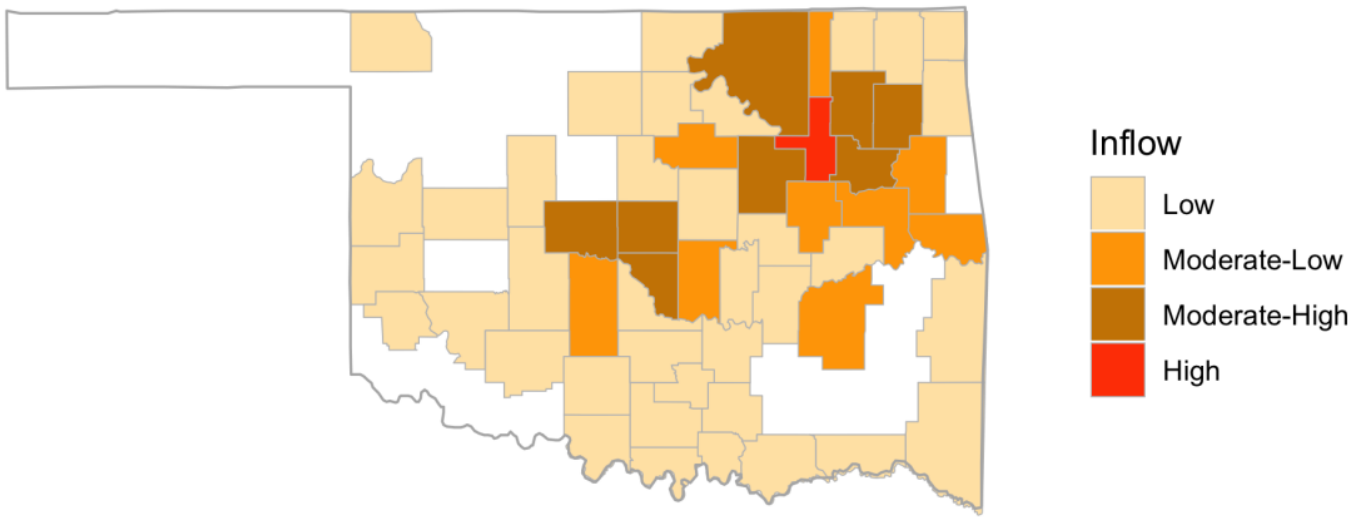

Panel (c): Distribution of Home Counties of Oklahomans and Border State Residents Who Traveled to Trump Event CBGs

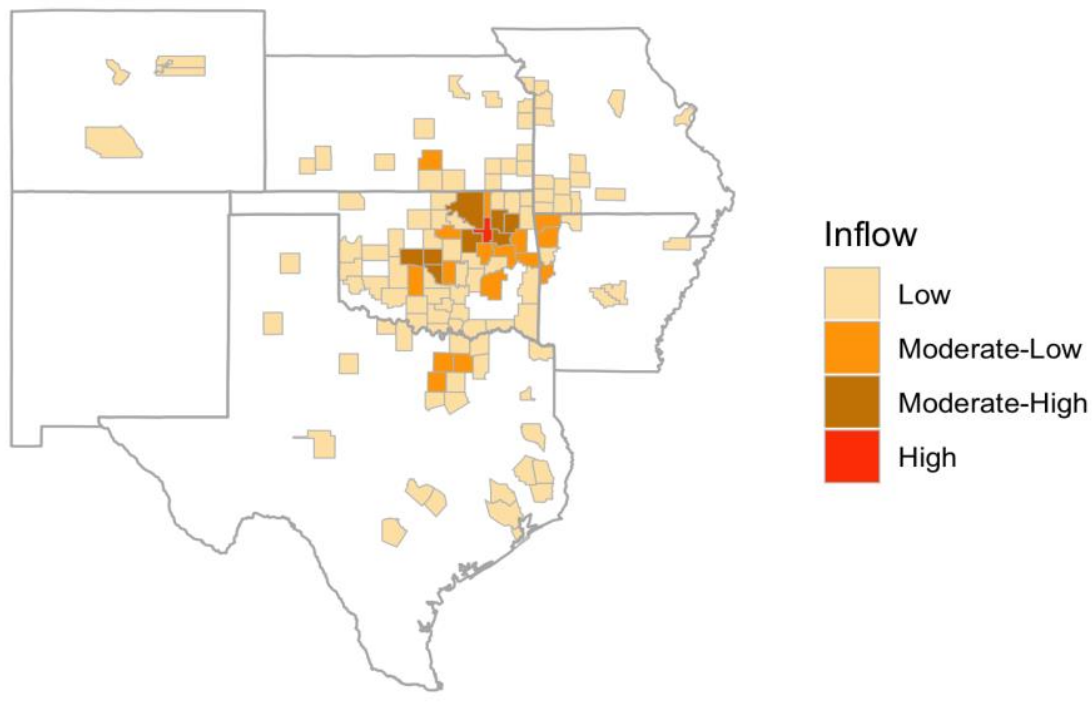




\section{Figure 2. Event-Study Analyses of Effect of Tulsa Rally on Non-Resident Ping Rate in Affected Census Block Groups}

Panel (a): Non-Resident Ping Rate

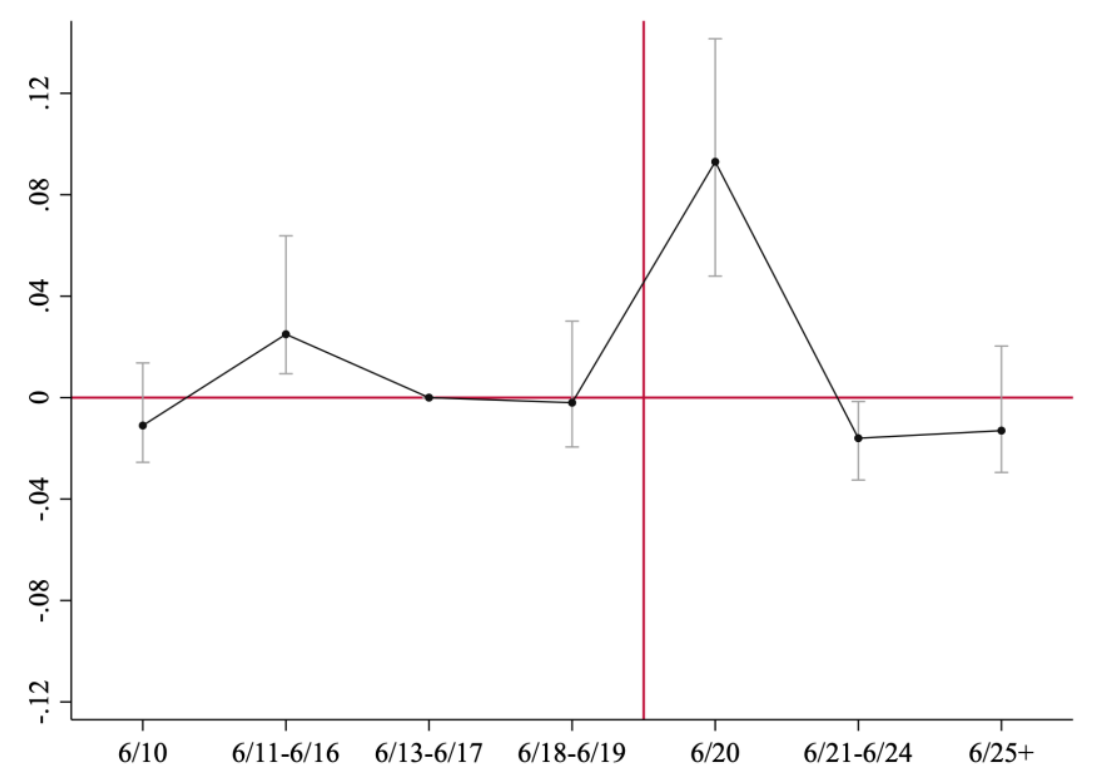

Panel (b): Total Ping Rate

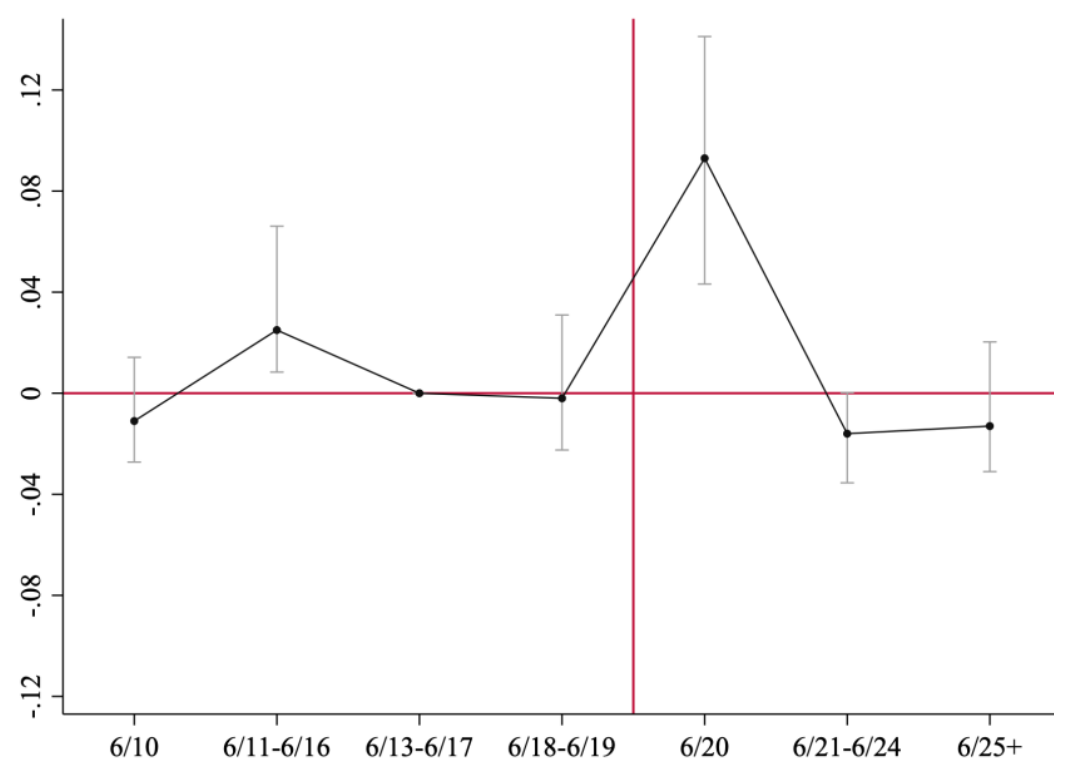

Note: Estimate is generated using weighted least squares estimate. All estimates include county and day fixed effects as well as county linear time trend. State policy controls include COVID-19 testing, an indicator for whether a state reopened restaurant or bars, an indicator for whether a state reopened retail services beyond curbside pickup, an indicator for whether a state reopened personal or pet care services, an indicator for whether a state reopened entertainment business, an indicator for whether a state reopened gyms or parks, and an indicator for whether a state paused reopening. County weather controls include average temperature and an indicator for whether any measurable precipitation fell. 


\section{Figure 3. Synthetic Control Estimates of Effect of Tulsa Rally on COVID-19 Cases and Deaths in Tulsa County}

Panel (a): Cases per 100,000 - Matching on Six days of Pre-Treatment COVID-19 Case Rates, Pre-Treatment Stay-at-Home Behavior, Mask Wearing Policy, and COVID-19 Reopening Policy

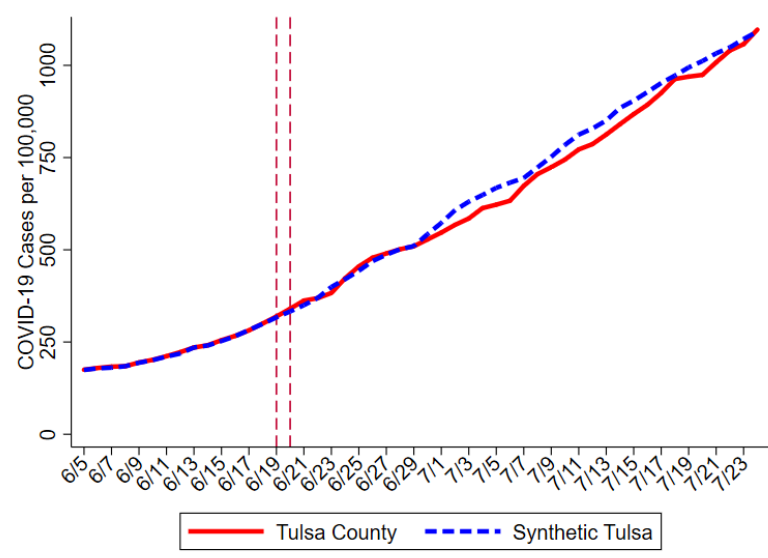

Panel (c): Cases per 100,000 - Matching on Six days of Pre-Treatment COVID19 Case Rates, Pre-Treatment Stay-at-Home Behavior, COVID-19 Testing Rate, COVID-19 Reopening Policy, and Mask Wearing Policy

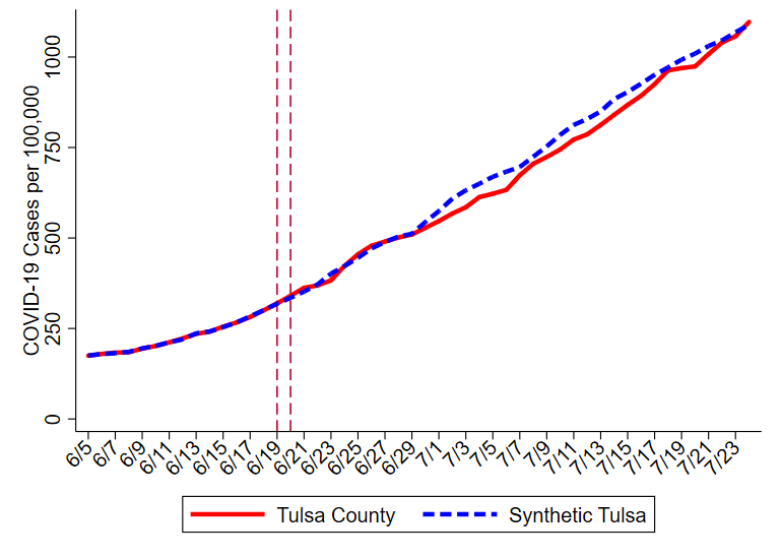

Panel (b): Deaths per 100,000 - Matching on Six days of Pre-Treatment COVID-19 Death Rates, Pre-Treatment Stay-at-Home Behavior, Mask Wearing Policy, and COVID-19 Reopening Policy

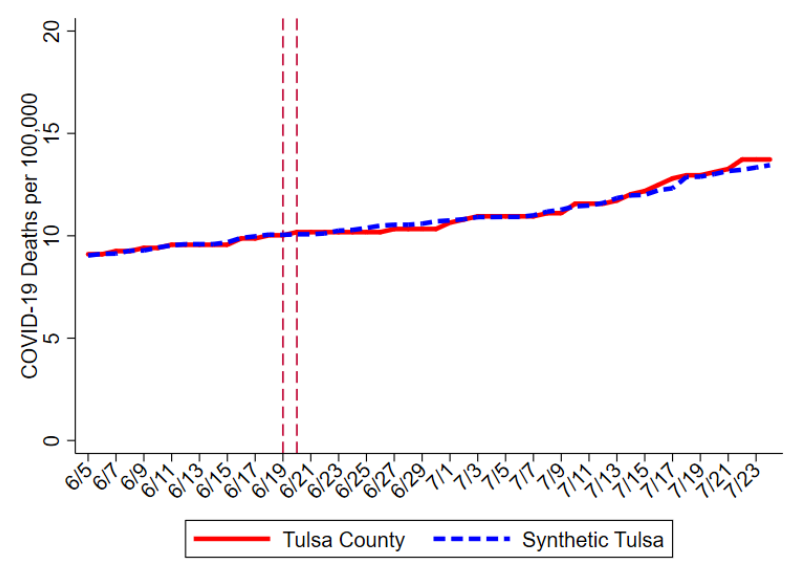

Panel (d): Deaths per 100,000 - Matching on Six days of Pre-Treatment COVID19 Death Rate, Pre-Treatment Stay-at-Home Behavior, COVID-19 Testing Rate, COVID-19 Reopening Policy, and Mask Wearing Policy

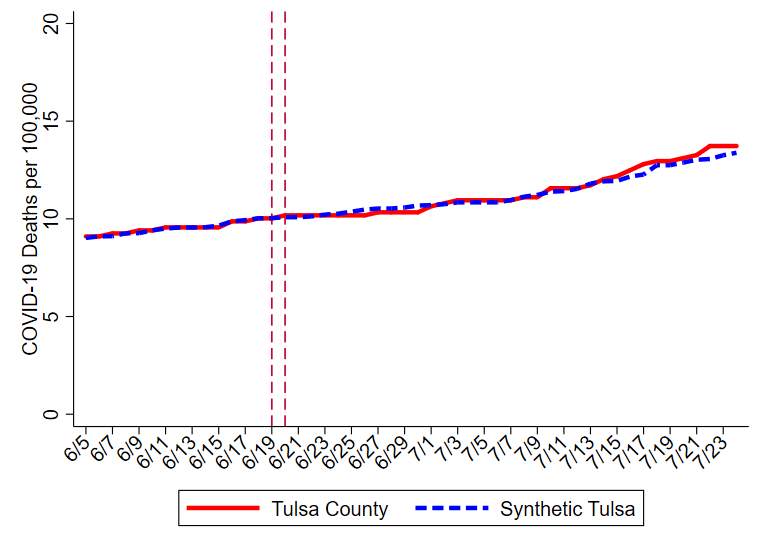

Note: The donor pool is comprised of primary counties (and their border counties) with urbanicity of \pm 2.5 Tulsa County's urbanicity rate (95.2\%) or weighted population density of $\pm 1,000$ Tulsa County's density $(3,250)$ and exclude counties in Oklahoma and in Oklahoma's border states, as well as counties where a home resident was detected (via smartphone using SafeGraph data) in the treatment CBGs on June 20, 2020. 


\section{Figure 4. Synthetic Control Estimates of Effect of Tulsa Rally on COVID-19 Cases and Deaths in Tulsa County Cluster}

Panel (a): Cases per 100,000 - Matching on Six days of Pre-Treatment COVID-19 Case Rates, Pre-Treatment Stay-at-Home Behavior, Mask Wearing Policy, and COVID-19 Reopening Policy

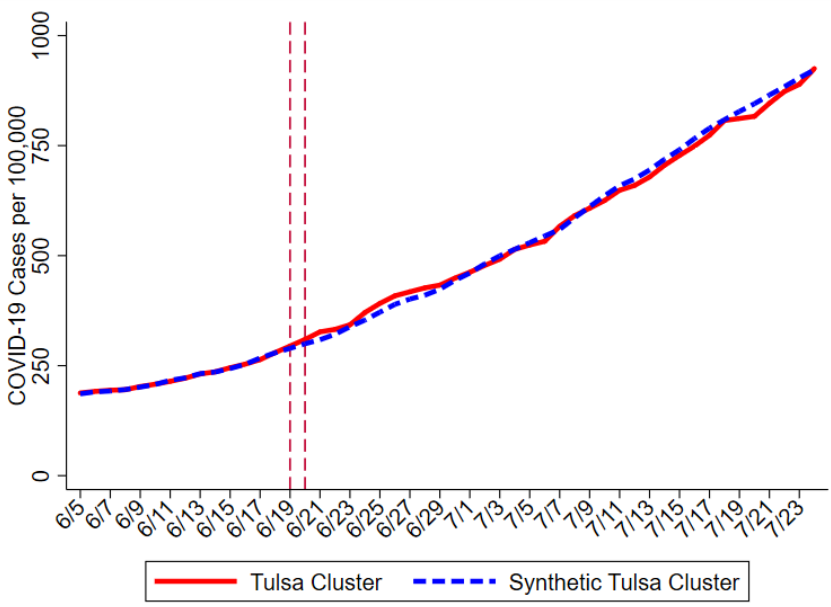

Panel (c): Cases per 100,000 - Matching on Six days of Pre-Treatment COVID19 Case Rates, Pre-Treatment Stay-at-Home Behavior, COVID-19 Testing Rate, COVID-19 Reopening Policy, and Mask Wearing Policy

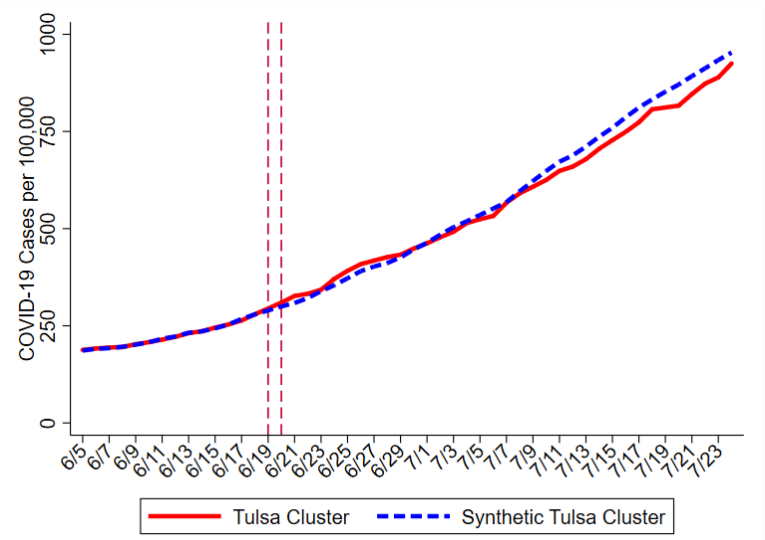

Panel (b): Deaths per 100,000 - Matching on Six days of Pre-Treatment COVID19 Death Rates, Pre-Treatment Stay-at-Home Behavior, Mask Wearing Policy, and COVID-19 Reopening Policy

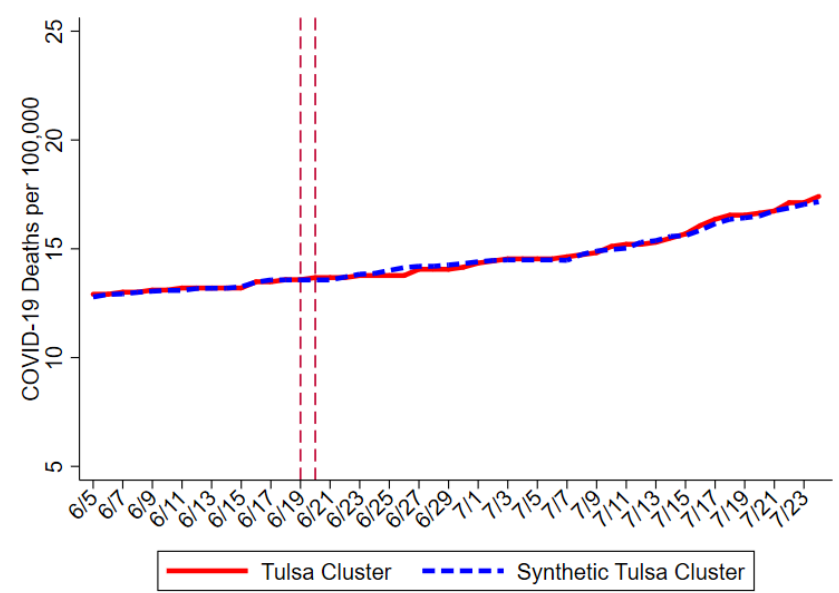

Panel (d): Deaths per 100,000 - Matching on Six days of Pre-Treatment COVID19 Death Rates, Pre-Treatment Stay-at-Home Behavior, COVID-19 Testing Rate, COVID-19 Reopening Policy, and Mask Wearing Policy

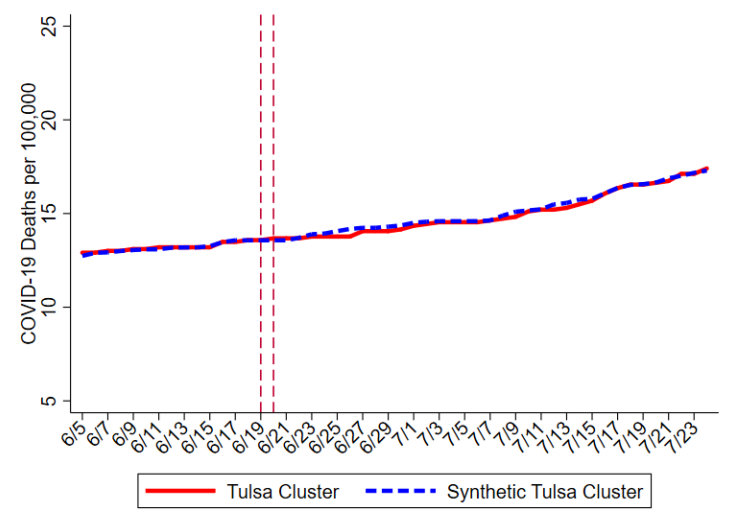

Note: The donor pool is comprised of primary counties (and their border counties) with urbanicity of \pm 2.5 Tulsa County's urbanicity rate (95.2\%) or weighted population density of $\pm 1,000$ Tulsa County's density $(3,250)$ and exclude counties in Oklahoma and in Oklahoma's border states, as well as counties where a home resident was detected (via smartphone using SafeGraph data) in the treatment CBGs on June 20, 2020. 
Figure 5. Synthetic Control Estimates of Effect of Tulsa Rally on COVID-19 Cases and Death in State of Oklahoma

Panel (a): Cases per 100,000 - Matching on Six days of Pre-Treatment COVID-19 Case Rates, Pre-Treatment Stay-at-Home Behavior, Mask Wearing Policy, and COVID-19 Reopening Policy

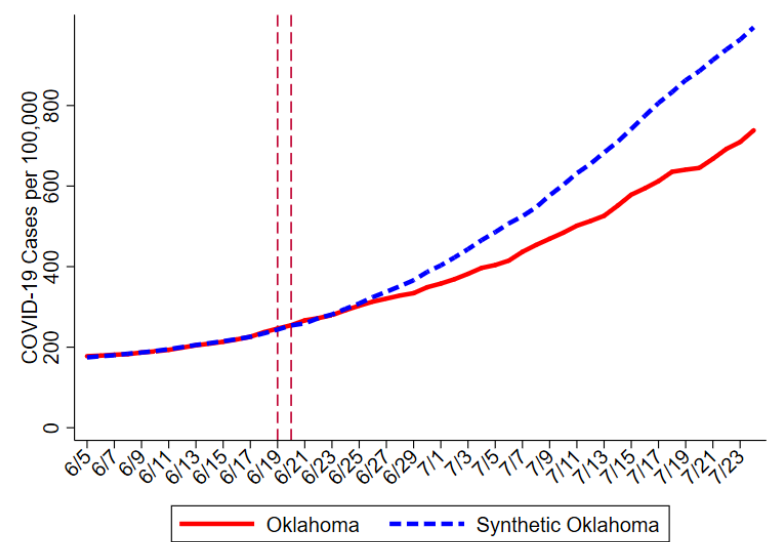

Panel (c): Cases per 100,000 - Matching on Six days of Pre-Treatment COVID19 Case Rates, Pre-Treatment Stay-at-Home Behavior, COVID-19 Testing Rate. COVID-19 Reopening Policy, and Mask Wearing Policy

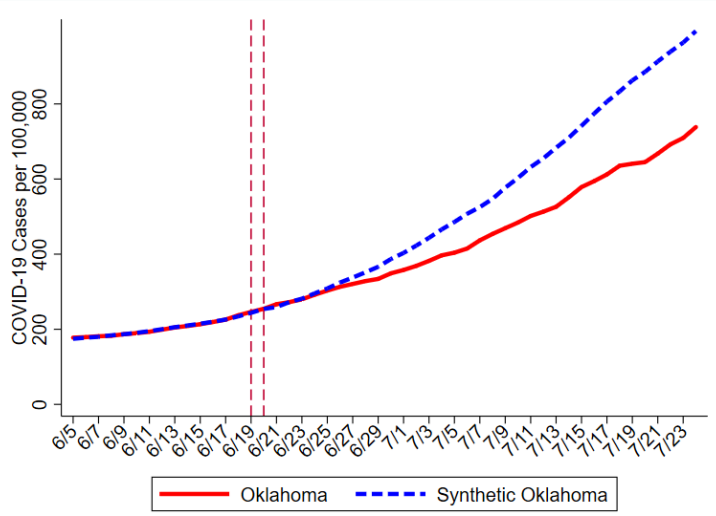

Panel (b): Deaths per 100,000-Matching on Six days of Pre-Treatment COVID-19 Death Rates, Pre-Treatment Stay-at-Home Behavior, Mask Wearing Policy, and COVID-19 Reopening Policy

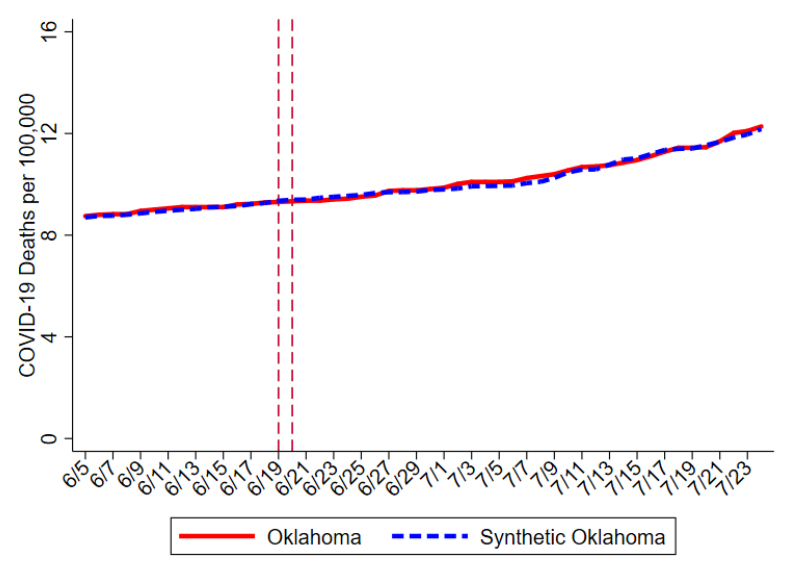

Panel (d): Deaths per 100,000 - Matching on Six days of Pre-Treatment Log(COVID-19 Case Rates), Pre-Treatment Stay-at-Home Behavior, COVID-19

Testing Rate, COVID-19 Reopening Policy, and Mask Wearing Policy

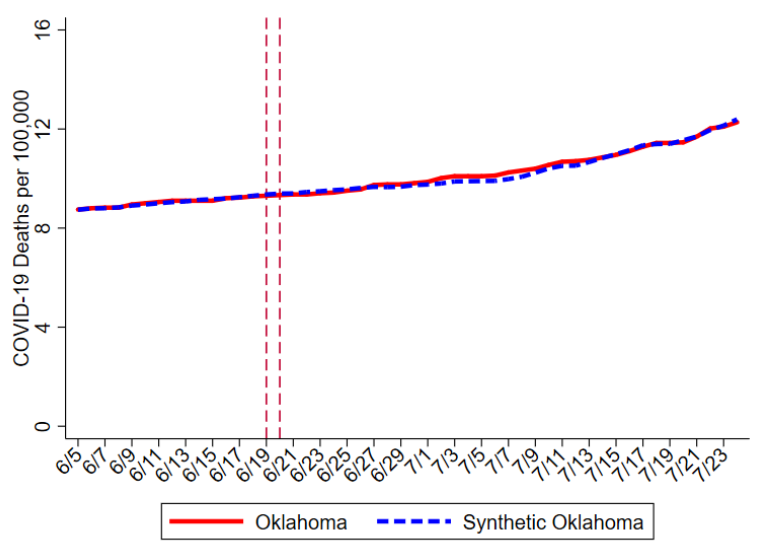

Note: The donor pool is comprised of states with urbanicity of \pm 15 Oklahoma's urbanicity rate $(65 \%)$ or with weighted population density \pm 750 Oklahoma's Population Density $(2,150)$ and exclude counties in Oklahoma and in Oklahoma's border states. 
Figure 6. Event-Study Analyses of Effect of Tulsa Rally on COVID-19 Cases Per 100,000 Population in Oklahoma and Border States, by Dose (Absolute Inflow)

Panel (a): Counties with Low Inflow

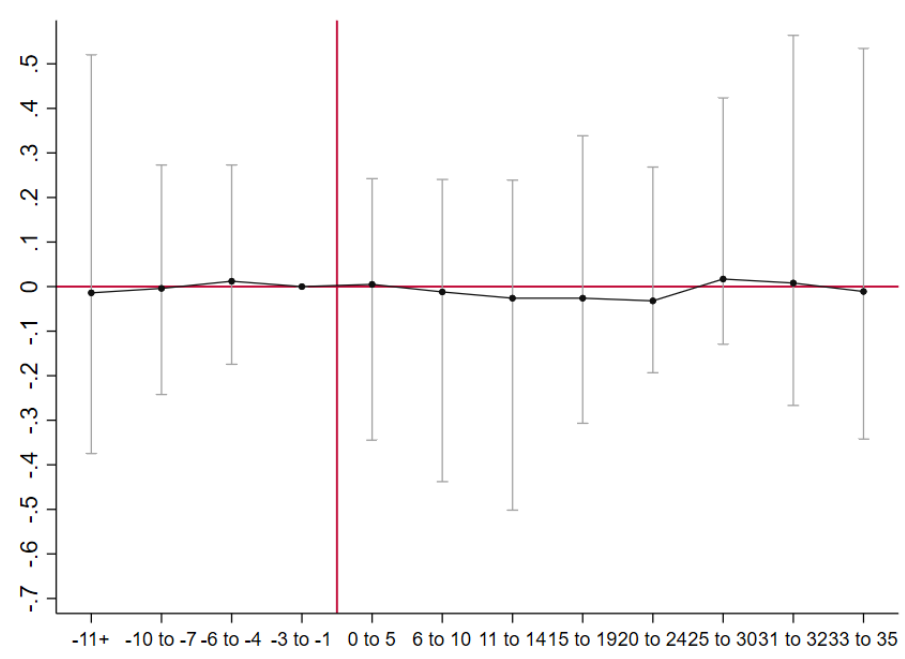

Panel (c): Counties with Moderate-High Inflow

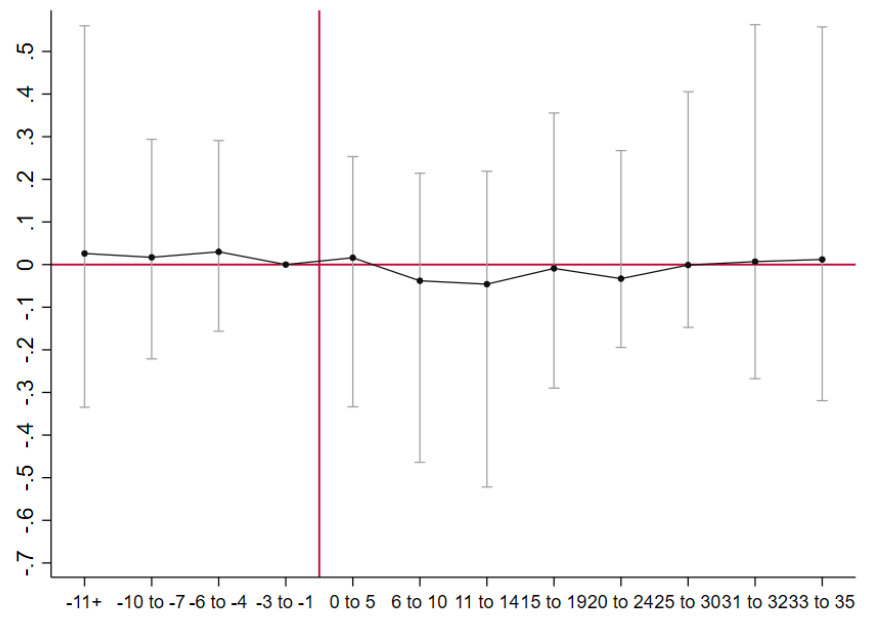

Panel (b): Counties with Moderate-Low Inflow

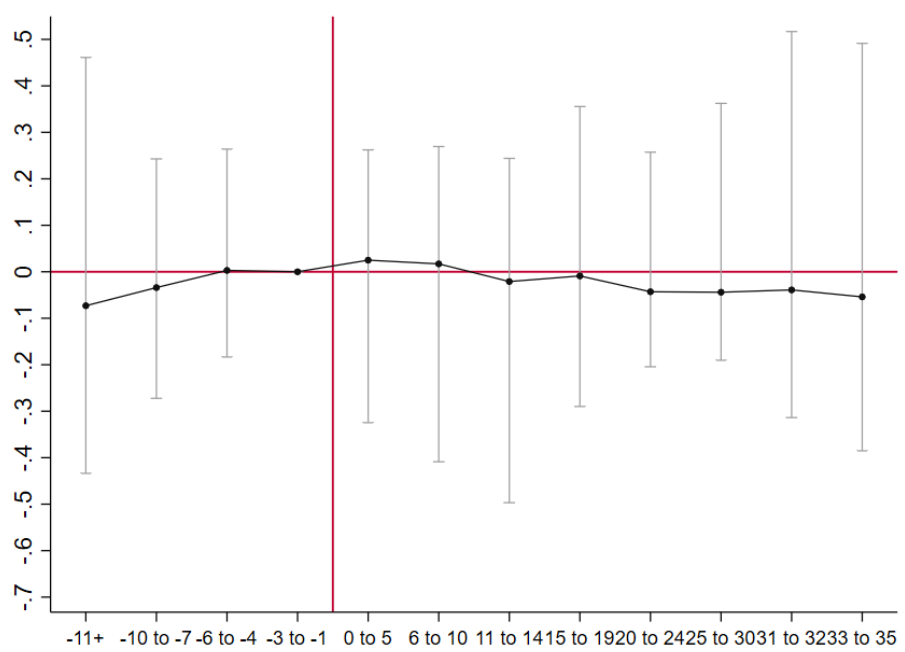

Panel (d): Highest Inflow County (Tulsa County)

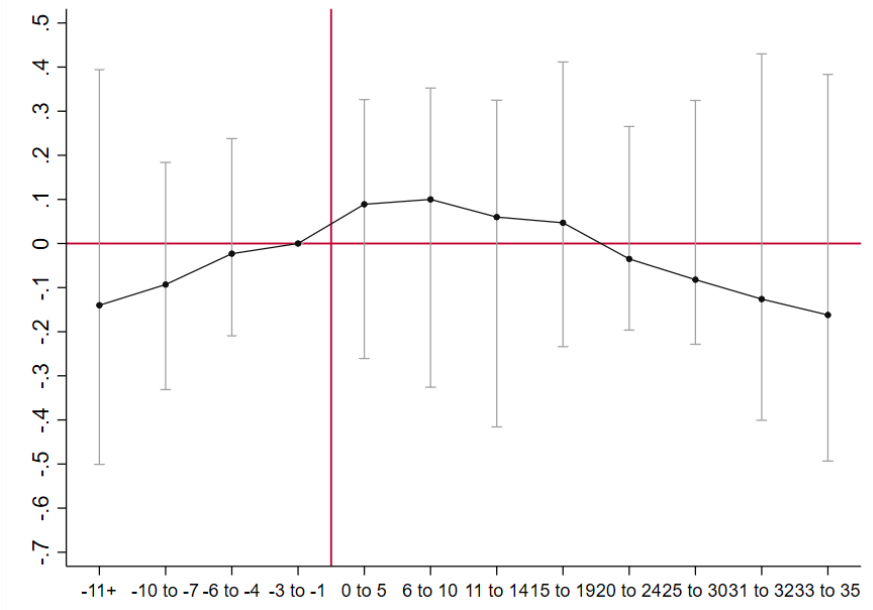

Note: Estimate is generated using weighted least squares estimate. All estimates include county and day fixed effects as well as county specific linear time trend. State policy controls include COVID-19 testing, an indicator for whether a state reopened restaurant or bars, an indicator for whether a state reopened retail services beyond curbside pickup, an indicator for whether a state reopened personal or pet care services, an indicator for whether a state reopened entertainment business, an indicator for whether a state reopened gyms or parks, and an indicator for whether a state paused reopening. County weather controls include average temperature and an indicator for whether any measurable precipitation fell. 


\section{Figure 7. Event-Study Analyses of Effect of Tulsa Rally on COVID-19 Deaths Per 100,000 Population in Oklahoma and}

Border States, by Dose (Absolute Inflow)

Panel (a): Counties with Low Inflow

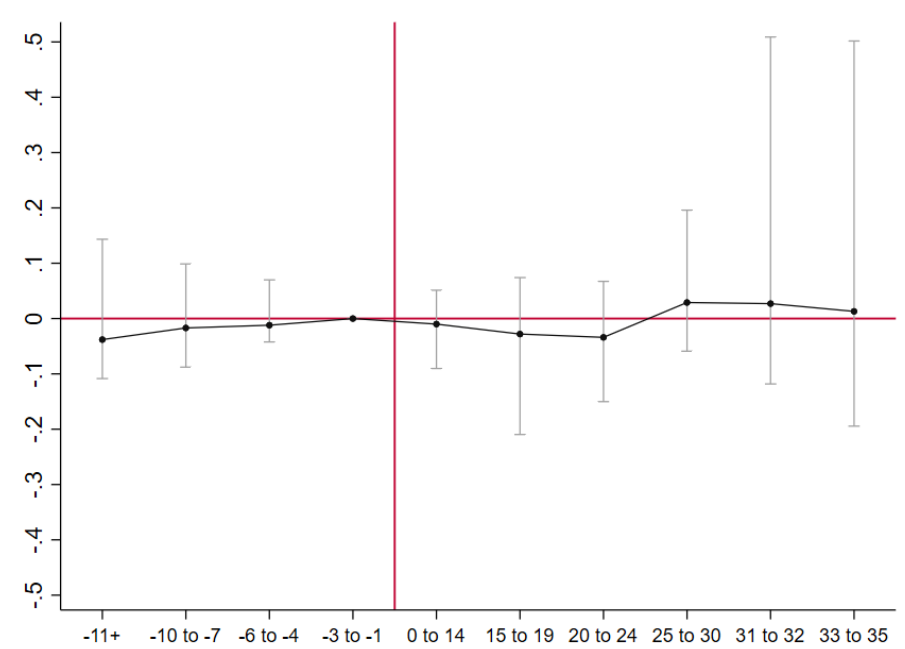

Panel (c): Counties with Moderate-High Inflow

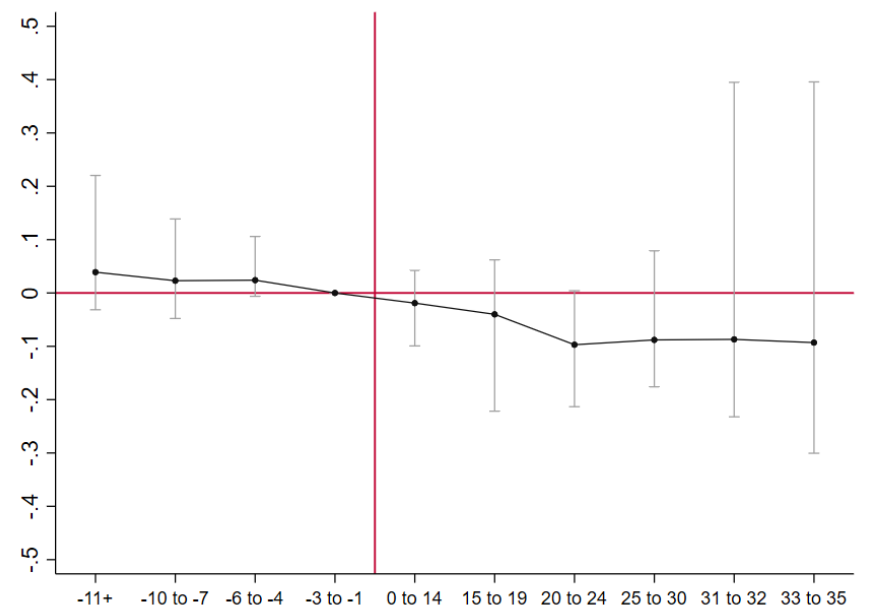

Panel (b): Counties with Moderate-Low Inflow

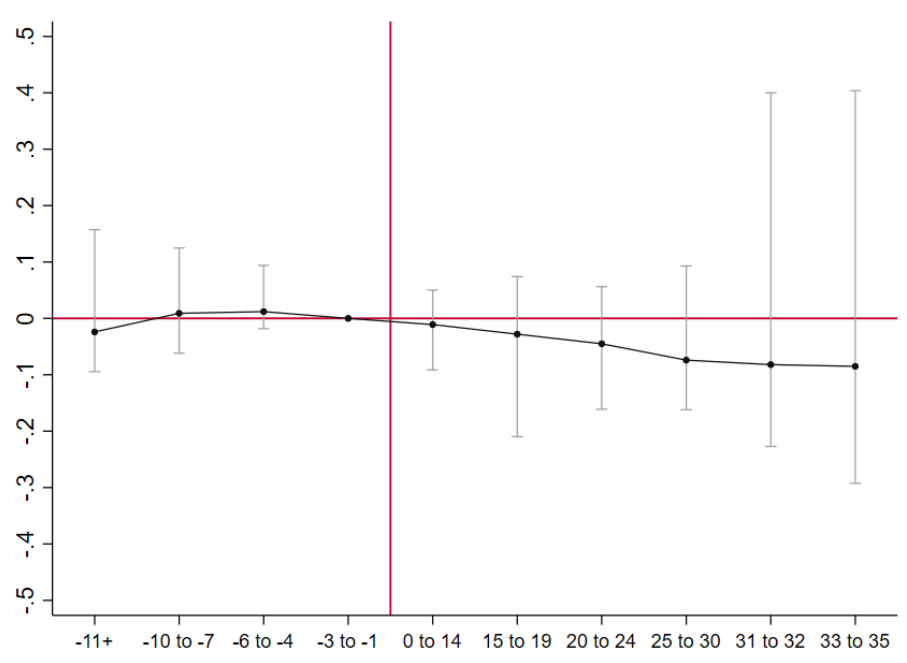

Panel (d): Highest Inflow County (Tulsa County)

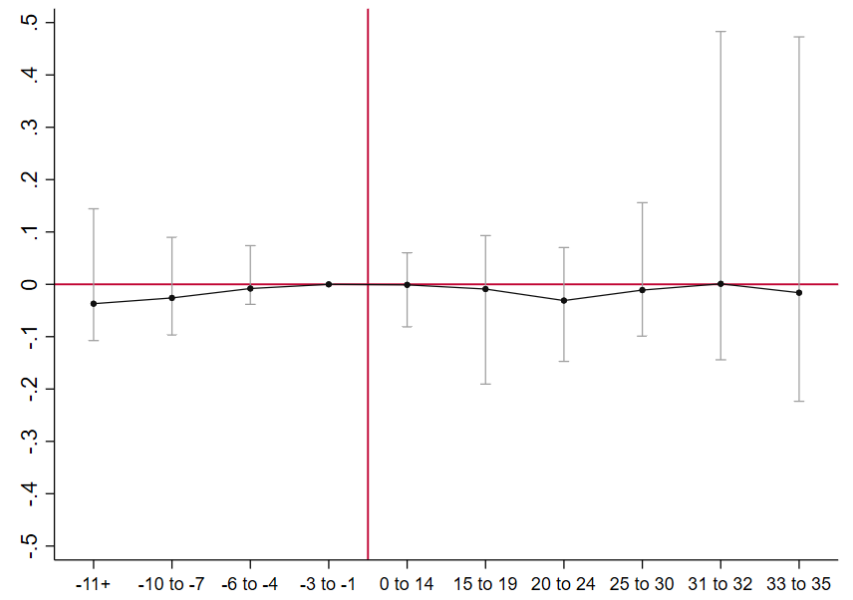

Note: Estimate is generated using weighted least squares estimate. All estimates include county and day fixed effects as well as county specific linear time trend. State policy controls include COVID-19 testing, an indicator for whether a state reopened restaurant or bars, an indicator for whether a state reopened retail services beyond curbside pickup, an indicator for whether a state reopened personal or pet care services, an indicator for whether a state reopened entertainment business, an indicator for whether a state reopened gyms or parks, and an indicator for whether a state paused reopening. County weather controls include average temperature and an indicator for whether any measurable precipitation fell. 


\section{Table 1. Difference-in-Differences Estimates of the Effect of Tulsa Rally on Pings per 1,000 Meters Squared in Treatment Census Block Groups}

\begin{tabular}{|c|c|c|c|c|}
\hline & (1) & (2) & (3) & (4) \\
\hline & \multicolumn{4}{|c|}{ Panel I: Non-Resident Pings } \\
\hline Trump Rally & $0.097 * *$ & $0.097 * *$ & $0.098 * *$ & $0.097 * *$ \\
\hline P-Value & {$[.017]$} & {$[.017]$} & {$[.017]$} & {$[.017]$} \\
\hline $\mathrm{N}$ & 68148 & 68148 & 68148 & 68148 \\
\hline \multirow[t]{2}{*}{ Mean of DV } & 0.377 & 0.377 & 0.377 & 0.377 \\
\hline & \multicolumn{4}{|c|}{ Panel II: Total Pings } \\
\hline Trump Rally & $0.092 * *$ & $0.091 * *$ & $0.091 * *$ & $0.092 * *$ \\
\hline P-Value & {$[.018]$} & {$[.018]$} & {$[.018]$} & {$[.018]$} \\
\hline $\mathrm{N}$ & 68148 & 68148 & 68148 & 68148 \\
\hline Mean of DV & 0.410 & 0.410 & 0.410 & 0.410 \\
\hline Day \& Census Block Group FE? & Yes & Yes & Yes & Yes \\
\hline COVID-19 Policy \& Weather Controls? & No & Yes & Yes & Yes \\
\hline BLM Protest Controls & No & No & Yes & Yes \\
\hline County Linear Time Trend & No & No & No & Yes \\
\hline
\end{tabular}

$*$ Significant at the $10 \%$ level, ** Significant at the 5\% level, *** Significant at the $1 \%$

Note: Estimate is generated using weighted least squares estimate. All estimates include county and day fixed effects as well as county specific linear time trend. State policy controls include COVID-19 testing, an indicator for whether a state reopened restaurant or bars, an indicator for whether a state reopened retail services beyond curbside pickup, an indicator for whether a state reopened personal or pet care services, an indicator for whether a state reopened entertainment business, an indicator for whether a state reopened gyms or parks, and an indicator for whether a state paused reopening. County weather controls include average temperature and an indicator for whether any measurable precipitation fell. BLM Controls include whether a county had a city with at least 100,000 population with a protest. Permutation based p-value is reported inside the bracket. 


\section{Table 2. Synthetic Control Estimates of Effect of Tulsa Rally on COVID-19 Cases}

\begin{tabular}{|c|c|c|c|}
\hline & $(1)$ & $(2)$ & (3) \\
\hline & \multicolumn{3}{|c|}{ Panel I: Tulsa County } \\
\hline Trump Rally & -20.290 & -20.747 & -36.902 \\
\hline P-Value & {$[0.580]$} & {$[0.541]$} & {$[0.502]$} \\
\hline \multirow[t]{2}{*}{ Pre-Treatment Mean of DV a } & 230.099 & 230.099 & 230.099 \\
\hline & \multicolumn{3}{|c|}{ Panel II: Tulsa County Cluster } \\
\hline Trump Rally & -2.017 & -13.288 & -14.833 \\
\hline P-Value & {$[0.888]$} & {$[0.766]$} & {$[0.829]$} \\
\hline \multirow[t]{2}{*}{ Pre-Treatment Mean of DV a } & 227.892 & 227.892 & 227.892 \\
\hline & \multicolumn{3}{|c|}{ Panel III: State of Oklahoma } \\
\hline Trump Rally & -106.378 & -106.41 & -104.474 \\
\hline P-Value & {$[0.174]$} & {$[0.174]$} & {$[0.304]$} \\
\hline Pre-Treatment Mean of DV a & 203.002 & 203.002 & 203.002 \\
\hline \multicolumn{4}{|l|}{ Observable used to construct the weights } \\
\hline Number of pre-treatment days & 6 & 6 & 14 \\
\hline Matching on Median Hours at Home & Yes & Yes & No \\
\hline Matching on Reopening Policy? & Yes & Yes & No \\
\hline Matching on Mask Wearing Policy? & Yes & Yes & No \\
\hline Matching COVID-testing? & No & Yes & No \\
\hline
\end{tabular}




\section{Table 3. Synthetic Control Estimates of Effect of Tulsa Rally on COVID-19 Deaths}

\begin{tabular}{|c|c|c|c|}
\hline \multirow[b]{3}{*}{ Trump Rally } & (1) & (2) & (3) \\
\hline & \multicolumn{3}{|c|}{ Panel I: Tulsa County } \\
\hline & -0.024 & 0.079 & -1.344 \\
\hline P-Value & {$[0.896]$} & {$[0.877]$} & {$[0.537]$} \\
\hline \multirow[t]{2}{*}{ Pre-Treatment Mean of DV a } & 9.542 & 9.542 & 9.542 \\
\hline & \multicolumn{3}{|c|}{ Panel II: Tulsa County Cluster } \\
\hline Trump Rally & 0.016 & -0.100 & -1.089 \\
\hline P-Value & {$[0.937]$} & [0.937] & {$[0.330]$} \\
\hline \multirow[t]{2}{*}{ Pre-Treatment Mean of DV a } & 13.210 & 13.210 & 13.210 \\
\hline & \multicolumn{3}{|c|}{ Panel III: State of Oklahoma } \\
\hline Trump Rally & 0.041 & 0.059 & 0.171 \\
\hline P-Value & {$[0.913]$} & {$[0.913]$} & {$[0.565]$} \\
\hline Pre-Treatment Mean of DV a & 9.044 & 9.044 & 9.044 \\
\hline \multicolumn{4}{|l|}{ Observable used to construct the weights } \\
\hline Number of pre-treatment days & 6 & 6 & 14 \\
\hline Matching on Median Hours at Home & Yes & Yes & No \\
\hline Matching on Reopening Policy? & Yes & Yes & No \\
\hline Matching on Mask Wearing Policy? & Yes & Yes & No \\
\hline Matching COVID-testing? & No & Yes & No \\
\hline
\end{tabular}


Table 4. Dose-Response Difference-in-Differences Estimates of the Effect of Tulsa Rally on Log (COVID-19 Cases)

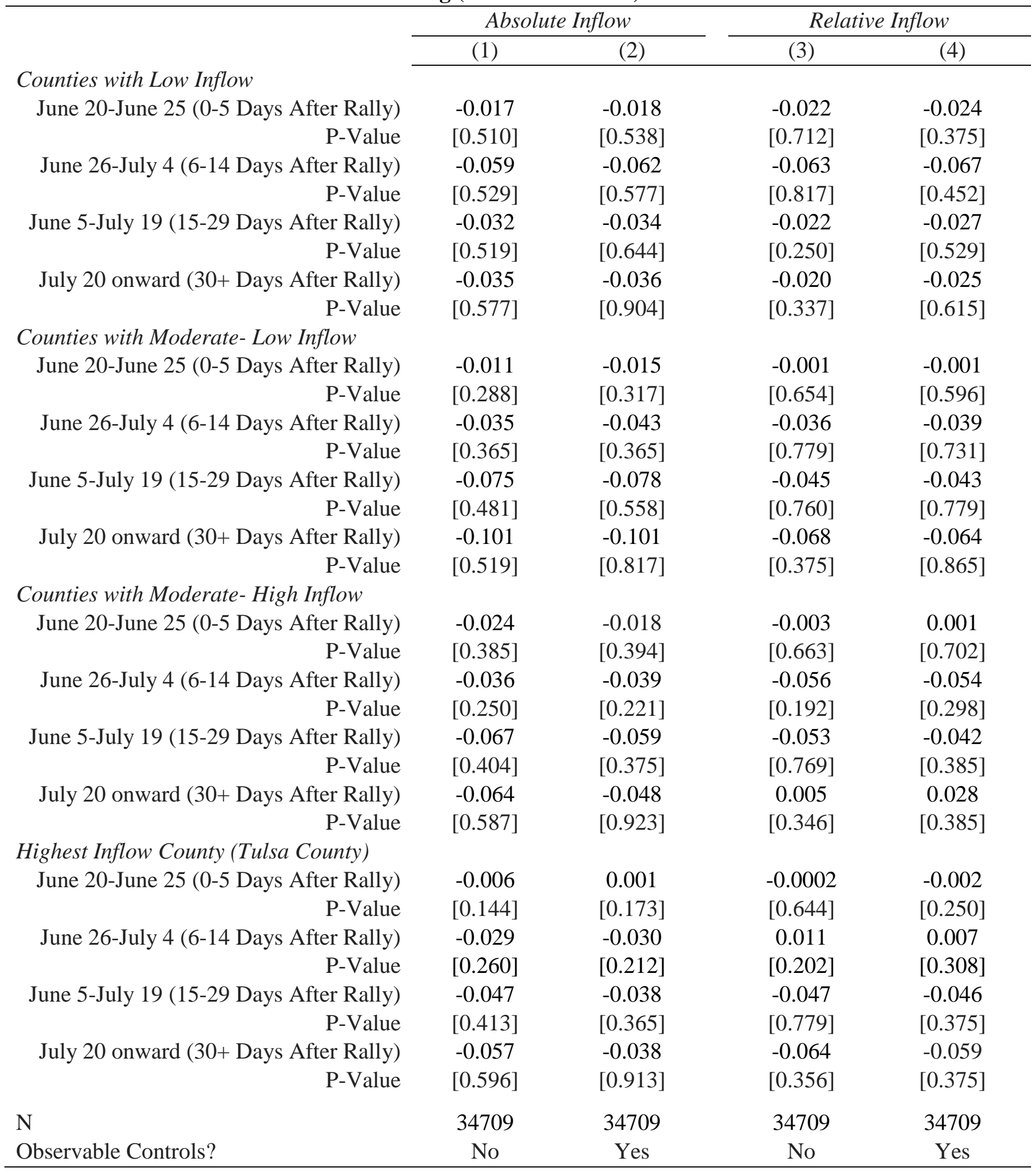


* Significant at the $10 \%$ level, ** Significant at the 5\% level, *** Significant at the $1 \%$ level

Note: Estimate is generated using weighted least squares estimate. All estimates include county and day fixed effects as well as county specific linear time trend. State policy controls include log COVID-19 testing, an indicator for whether a state reopened restaurant or bars, an indicator for whether a state reopened retail services beyond curbside pickup, an indicator for whether a state reopened personal or pet care services, an indicator for whether a state reopened entertainment business, an indicator for whether a state reopened gyms, and an indicator for whether a state paused reopening. County weather controls include average temperature and an indicator for whether any measurable precipitation fell. BLM Protest control include an indicator for whether a county had a city with 100,000 or more population with a Black Lives Matter protest. Permutation based p-value are included inside the bracket below each point estimate (Buchmueller et al. 2011; Cunningham and Shah 2018). 
Table 5. Dose-Response Difference-in-Differences Estimates of the Effect of Tulsa Rally on Inverse Hyperbolic Sine of COVID-19 Deaths

\begin{tabular}{|c|c|c|c|c|}
\hline & \multicolumn{2}{|c|}{ Absolute Inflow } & \multicolumn{2}{|c|}{ Relative Inflow } \\
\hline & (1) & (2) & (3) & (4) \\
\hline \multicolumn{5}{|l|}{ Counties with Low Inflow } \\
\hline June 20-July 4 (0-14 Days After Rally) & -0.017 & -0.018 & -0.022 & -0.024 \\
\hline P-Value & {$[0.740]$} & {$[0.760]$} & {$[0.712]$} & [0.837] \\
\hline June 26-July 10 (6-20 Days After Rally) & -0.059 & -0.062 & -0.063 & -0.067 \\
\hline P-Value & {$[0.817]$} & {$[0.846]$} & {$[0.817]$} & {$[0.865]$} \\
\hline June 11-July 19 (21-29 Days After Rally) & -0.032 & -0.034 & -0.022 & -0.025 \\
\hline P-Value & {$[0.202]$} & {$[0.240]$} & {$[0.250]$} & [0.212] \\
\hline July 20 onward (30+ Days After Rally) & -0.035 & -0.036 & -0.027 & -0.032 \\
\hline P-Value & {$[0.240]$} & {$[0.317]$} & {$[0.337]$} & [0.231] \\
\hline \multicolumn{5}{|l|}{ Counties with Moderate- Low Inflow } \\
\hline June 20-July 4 (0-14 Days After Rally) & -0.011 & -0.015 & -0.001 & -0.001 \\
\hline P-Value & {$[0.712]$} & {$[0.740]$} & {$[0.654]$} & {$[0.731]$} \\
\hline June 26-July 10 (6-20 Days After Rally) & -0.035 & -0.043 & -0.036 & -0.039 \\
\hline P-Value & {$[0.788]$} & {$[0.760]$} & {$[0.779]$} & [0.846] \\
\hline June 11-July 19 (21-29 Days After Rally) & -0.075 & -0.078 & -0.045 & -0.043 \\
\hline P-Value & {$[0.808]$} & {$[0.673]$} & {$[0.760]$} & [0.346] \\
\hline July 20 onward (30+ Days After Rally) & -0.101 & -0.101 & -0.068 & -0.064 \\
\hline P-Value & {$[0.279]$} & {$[0.596]$} & {$[0.375]$} & [0.317] \\
\hline \multicolumn{5}{|l|}{ Counties with Moderate- High Inflow } \\
\hline June 20-July 4 (0-14 Days After Rally) & -0.024 & -0.018 & -0.003 & 0.001 \\
\hline P-Value & {$[0.779]$} & {$[0.779]$} & {$[0.663]$} & {$[0.740]$} \\
\hline June 26-July 10 (6-20 Days After Rally) & -0.029 & -0.039 & -0.056 & -0.054 \\
\hline P-Value & {$[0.769]$} & {$[0.721]$} & {$[0.192]$} & [0.317] \\
\hline June 11-July 19 (21-29 Days After Rally) & -0.047 & -0.059 & -0.053 & -0.042 \\
\hline P-Value & {$[0.212]$} & {$[0.346]$} & {$[0.769]$} & [0.404] \\
\hline July 20 onward (30+ Days After Rally) & -0.057 & -0.048 & 0.005 & 0.028 \\
\hline P-Value & {$[0.260]$} & {$[0.346]$} & {$[0.346]$} & [0.308] \\
\hline \multicolumn{5}{|l|}{ Highest Inflow County (Tulsa County) } \\
\hline June 20-July 4 (0-14 Days After Rally) & -0.006 & 0.001 & 0.001 & -0.002 \\
\hline P-Value & {$[0.702]$} & [0.692] & {$[0.644]$} & {$[0.721]$} \\
\hline June 26-July 10 (6-20 Days After Rally) & -0.029 & -0.030 & 0.011 & 0.007 \\
\hline P-Value & {$[0.779]$} & {$[0.731]$} & {$[0.202]$} & [0.308] \\
\hline June 11-July 19 (21-29 Days After Rally) & -0.047 & -0.038 & -0.047 & -0.046 \\
\hline P-Value & {$[0.221]$} & {$[0.337]$} & {$[0.779]$} & [0.394] \\
\hline July 20 onward (30+ Days After Rally) & -0.057 & -0.038 & -0.064 & -0.059 \\
\hline P-Value & {$[0.269]$} & {$[0.356]$} & {$[0.356]$} & [0.298] \\
\hline $\mathrm{N}$ & 36873 & 36873 & 36873 & 36873 \\
\hline Observable Controls? & No & Yes & No & Yes \\
\hline
\end{tabular}


* Significant at the $10 \%$ level, ** Significant at the 5\% level, *** Significant at the $1 \%$ level

Note: Estimate is generated using weighted least squares estimate. All estimates include county and day fixed effects as well as county specific linear time trend. State policy controls include log COVID-19 testing, an indicator for whether a state reopened restaurant or bars, an indicator for whether a state reopened retail services beyond curbside pickup, an indicator for whether a state reopened personal or pet care services, an indicator for whether a state reopened entertainment business, an indicator for whether a state reopened gyms, and an indicator for whether a state paused reopening. County weather controls include average temperature and an indicator for whether any measurable precipitation fell. BLM Protest control include an indicator for whether a county had a city with 100,000 or more population with a Black Lives Matter protest. Permutation based p-value are included inside the bracket below each point estimate (Buchmueller et al. 2011; Cunningham and Shah 2018). 
Appendix Figure 1: Trends in Non-Resident Absolute Pings in the Treatment CBGs and "Control" CBGs

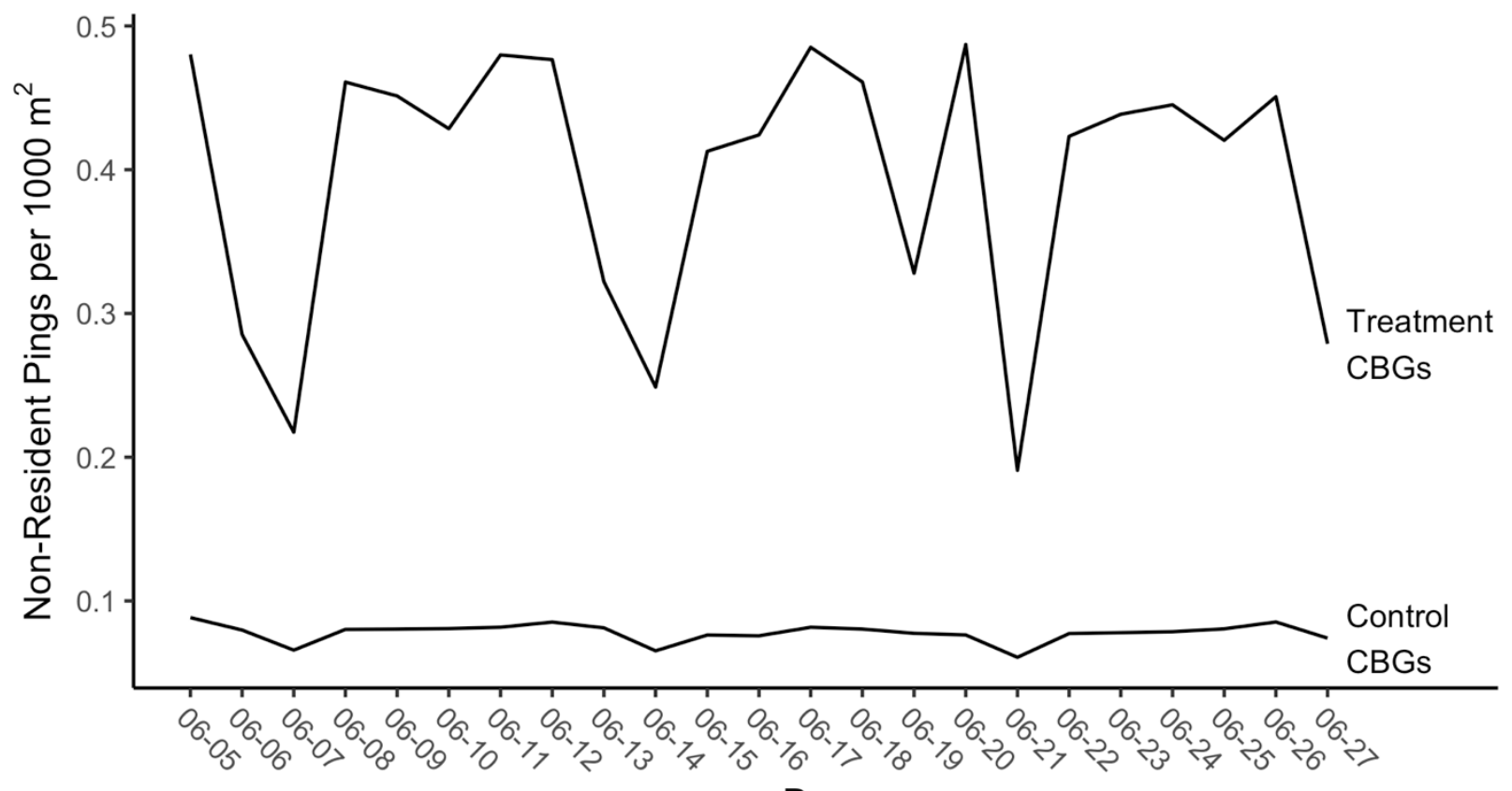

Day 


\section{Appendix Figure 2A. Distribution of Home Counties for Absolute Inflows to}

Treatment Census Block Groups on June 6, 2020

Panel (a): Home Counties Across U.S.

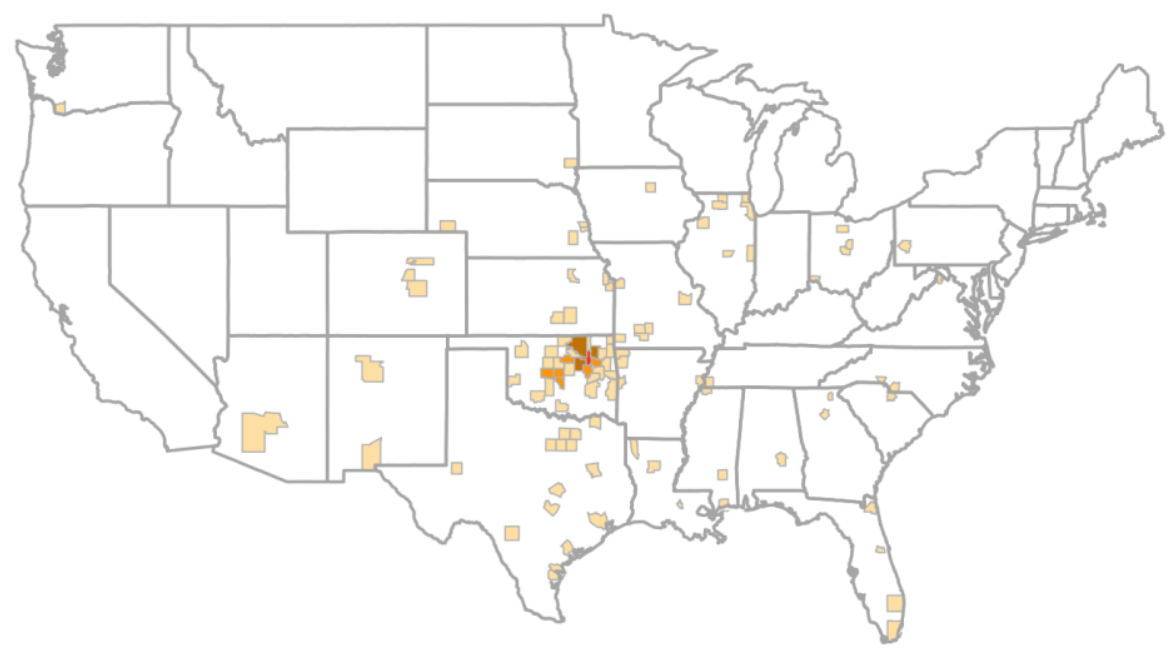

Inflow

Panel (b): Home Counties Across Oklahoma

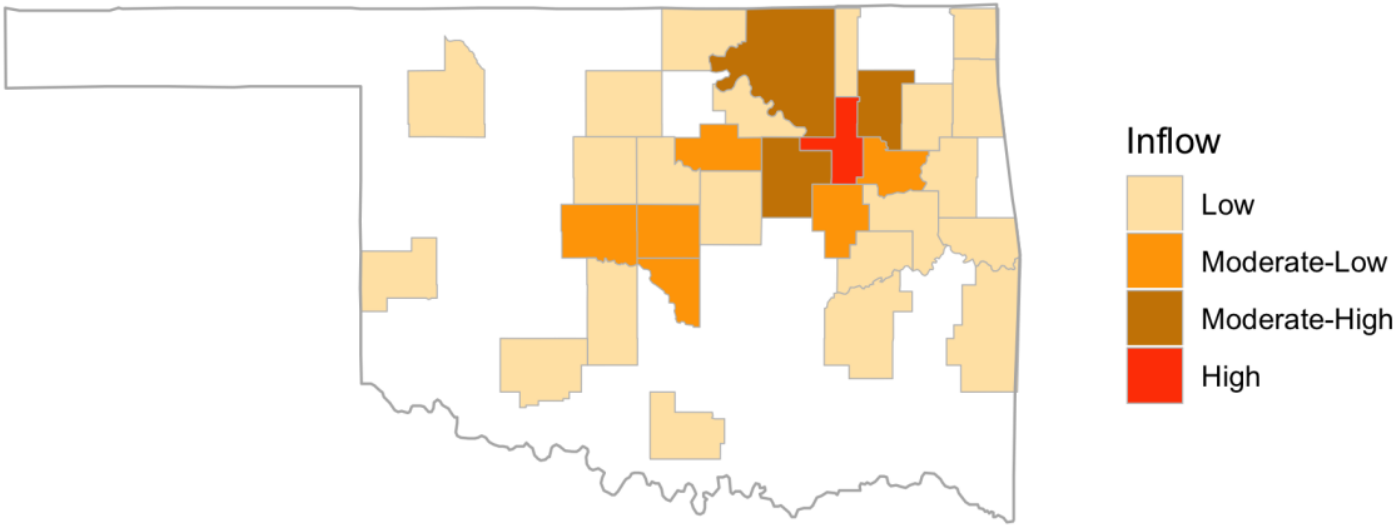

Panel (c): Home Counties Across Oklahoma and Border States

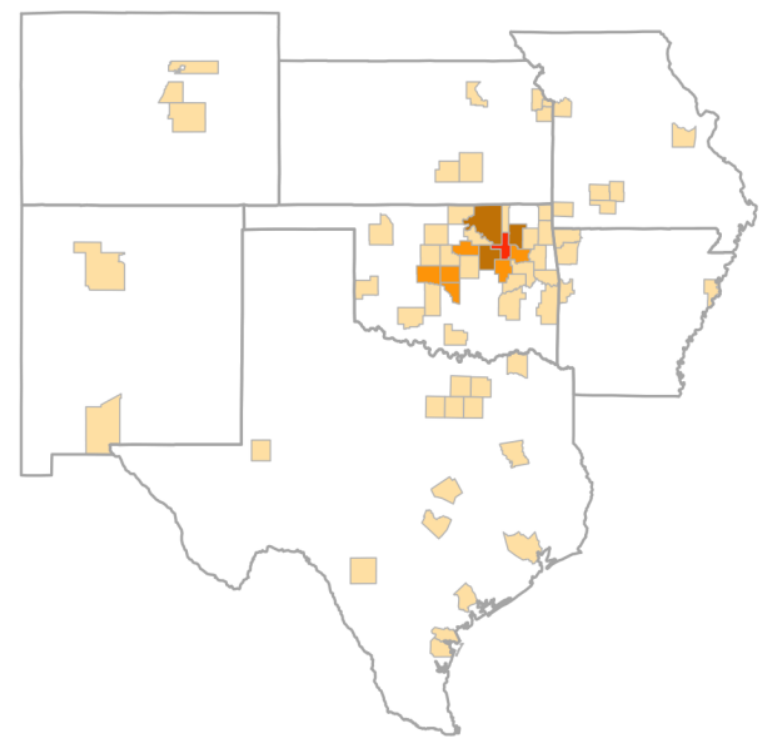

Inflow

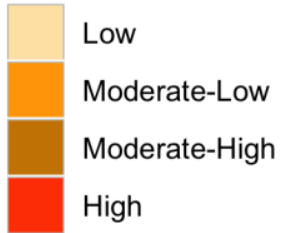




\section{Appendix Figure 2B. Distribution of Home Counties for Absolute Inflows to}

Treatment Census Block Groups on June 13, 2020

Panel (a): Home Counties Across U.S.

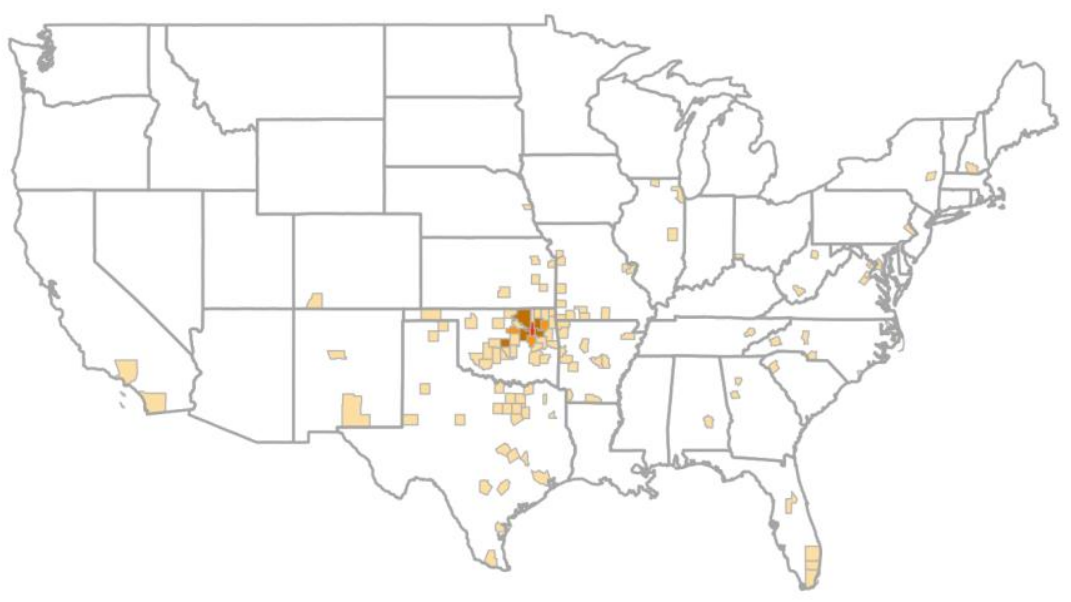

Inflow

Panel (b): Home Counties Across Oklahoma

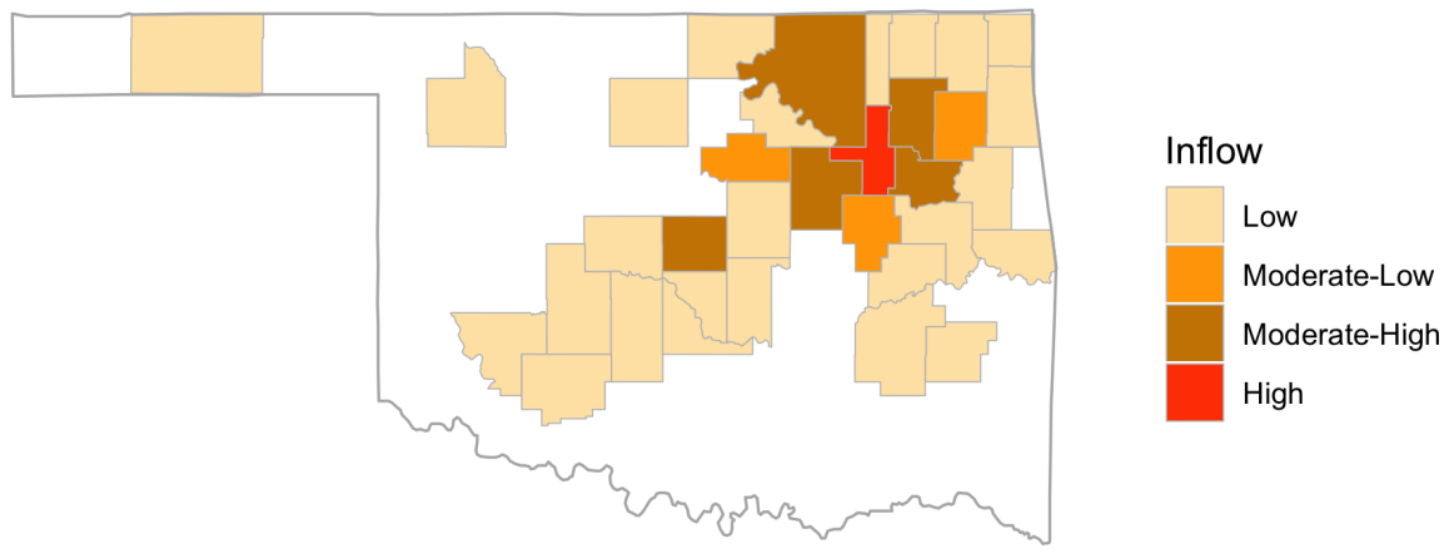

Panel (c): Home Counties Across Oklahoma and Border States

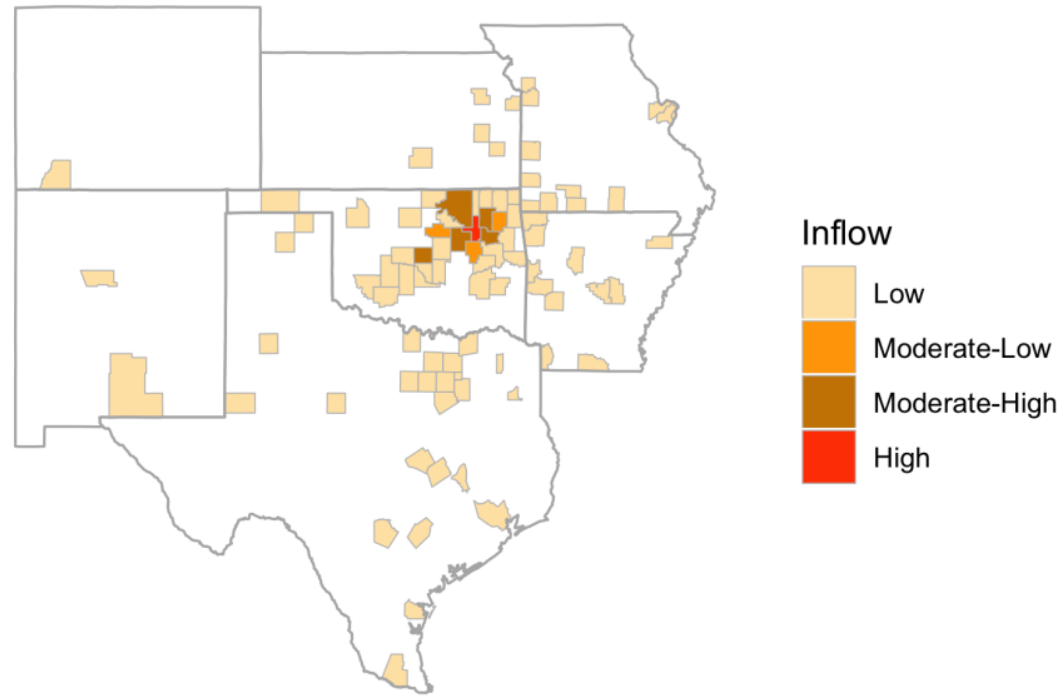


Appendix Figure 3A: Trends in COVID-19 Cases in Oklahoma, Tulsa County and Tulsa County Cluster

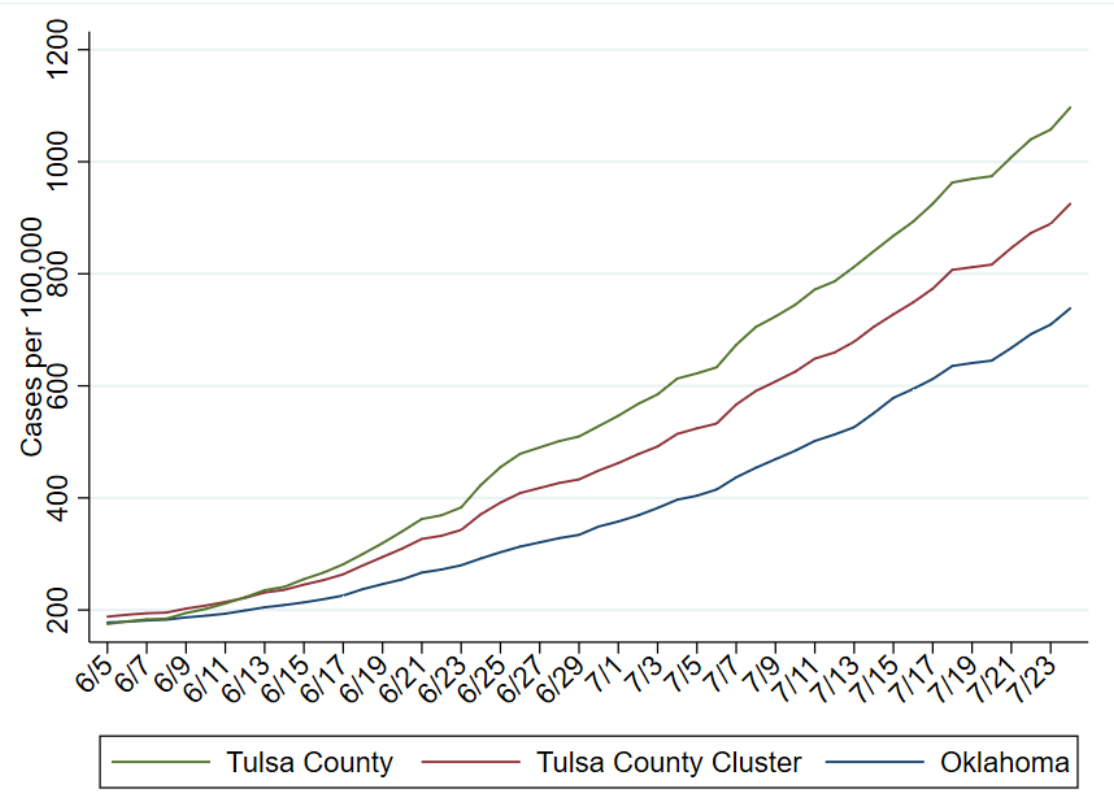


Appendix Figure 3B: Trends in COVID-19 Deaths in Oklahoma, Tulsa County and Tulsa County Cluster

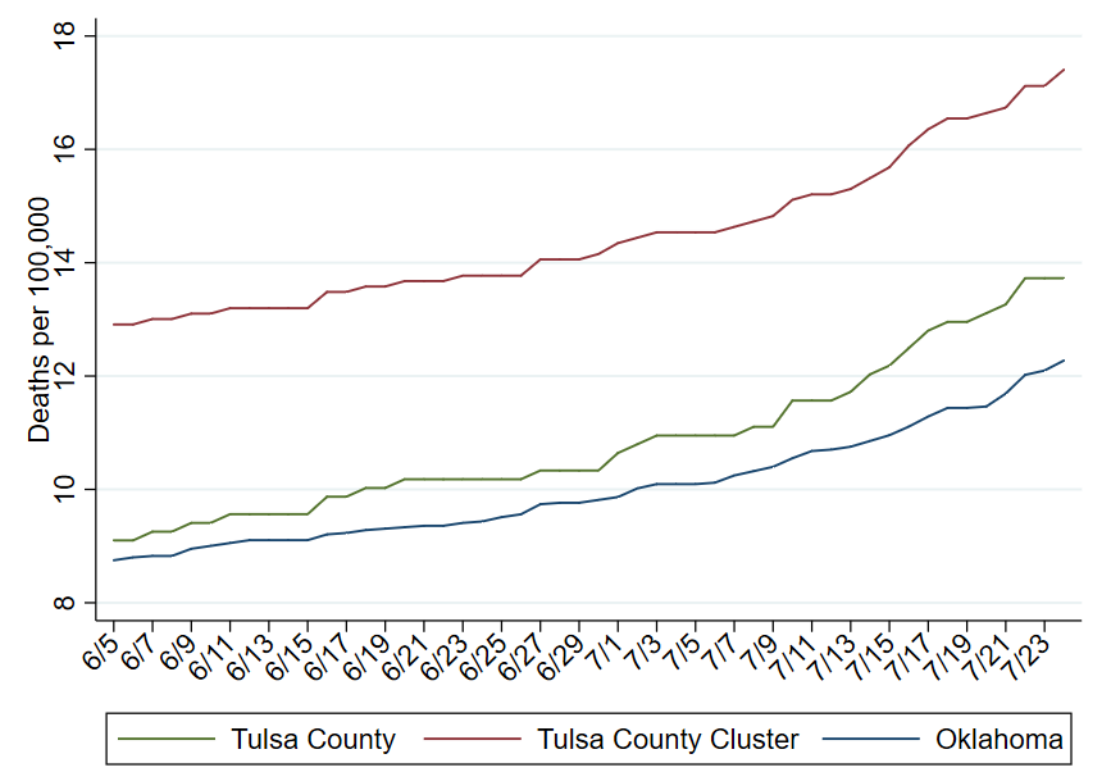


Appendix Figure 4. Distribution of Home Counties for Relative Inflows to Treatment Census Block Groups on June 20, 2020

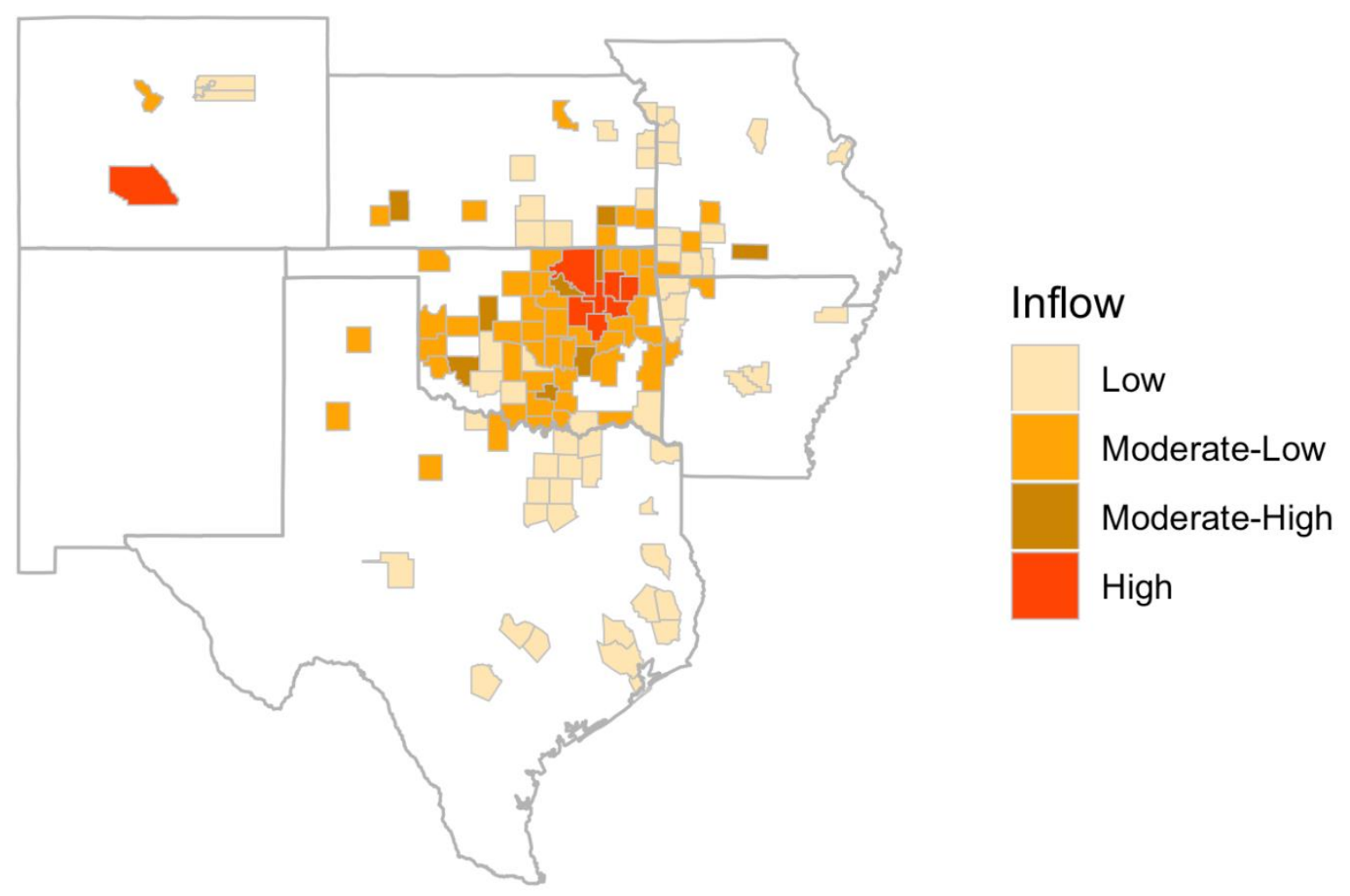




\section{Appendix Figure 5. Synthetic Control Estimates of Effects of Tulsa Rally on Stay-at-Home Behavior in Tulsa County Cluster}

Panel (a): \% Staying at Home Full Time

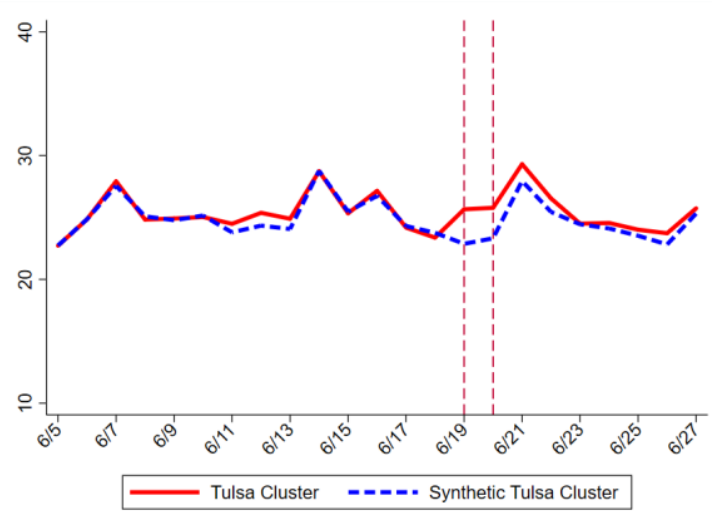

Note: Synthetic Tulsa is comprised of Jefferson, AL (.347), Burleigh, ND (.227), Coles, IL (.142), Cabell, WV (.137), Dorchester, SC (.105), \& Colonial Heights, VA (.035).

\section{Panel (c): Median Hours at Home}

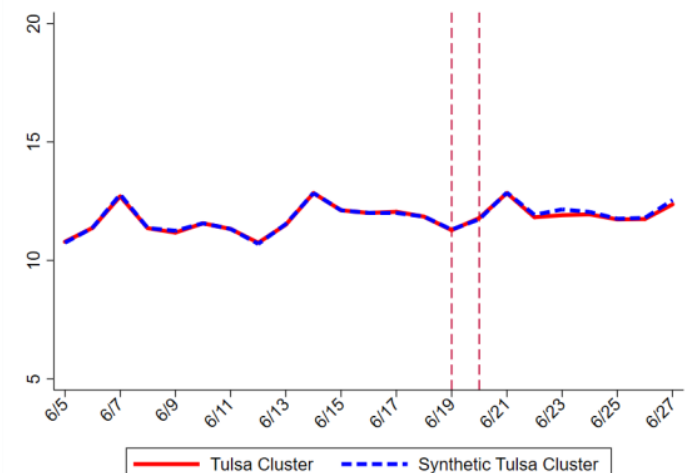

Note: Synthetic Tulsa is comprised of Jefferson, AL (.373), Cabell, WV (.202), Monongalia, WV (.094). Linn, IA (.085), Pinal, AZ (.081), Dorchester, SC (.078), Carcon, NV (.039), \& Outaagamie, WI (.036)
Panel (b): Median \% Time at Home

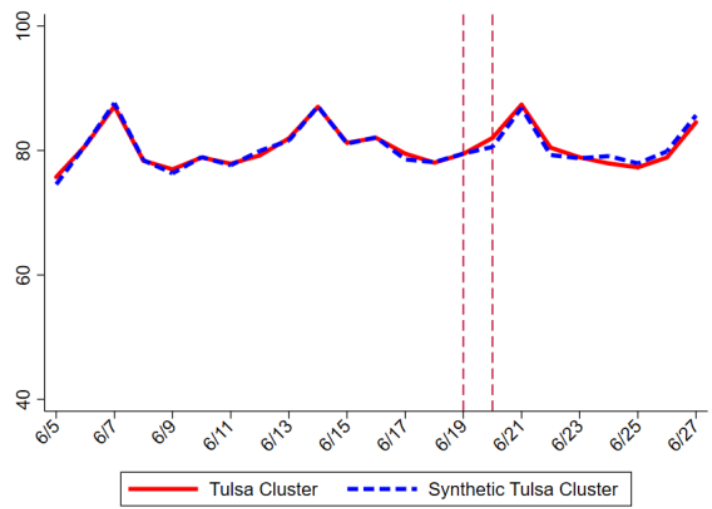

Note: Synthetic Tulsa is comprised of Chatham, GA (.34), Jefferson, AL (.128), Cascade, MT (.113), Lafayette, LA (.086), Cabell, WV (.075), Coconino, AZ (.072), Silver Bow, MT (.066), Winona, MN (.063), and Albany, NY (.032).

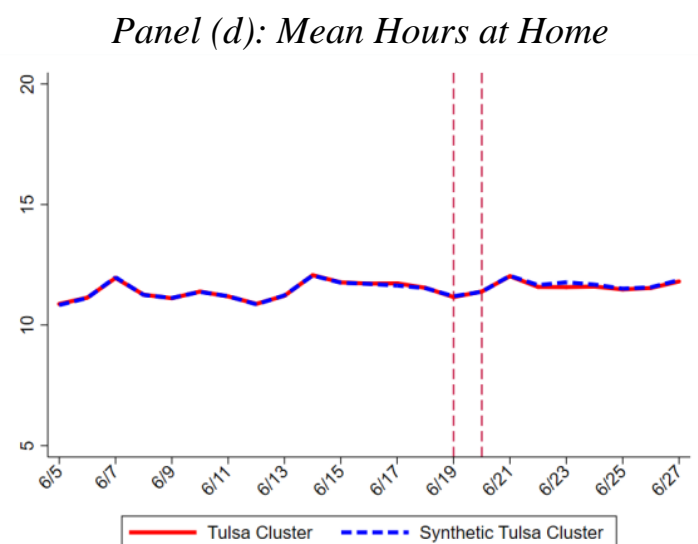

Note: Synthetic Tulsa is comprised of Dorchesterm SC (.209), Jefferson, AL (.197), Cabell, WV (.196), Pinal, AZ (.159), Linn IA (.082), Carson NV (.080), \& Anchorage, AK (.071)

Note: The donor counties are comprised of counties with urbanicity rate of \pm 2.5 Tulsa County's urbanicity rate (95.2\%) or weighted population density of $\pm 1,000$ Tulsa County's density $(3,250)$ and exclude counties in Oklahoma and in Oklahoma's border states, as well as counties where a home resident was detected (via smartphone using SafeGraph data) in the treatment CBGs on June 20, 2020. Matching was based on six pre-treatment social distancing behaviors, COVID-19 testing rate, COVID-19 reopening policies, and mask wearing policies 


\section{Appendix Figure 6. Synthetic Control Estimates of Effects of Tulsa Rally on Stay-at-Home Behavior in Tulsa County}

Panel (a): \% Staying at Home Full Time

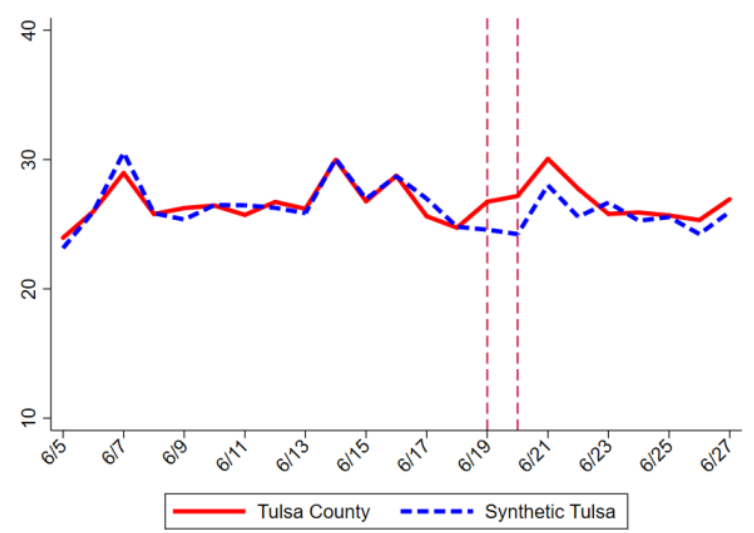

Note: Synthetic Tulsa is comprised of Silver Bow, MT (.253), Indiana, PA (.161), Wayne, NE (.142), Jefferson, AL (.128), Lafayette, LA (.108), Colonial Heights, VA (.087), Sweetwater, WY (.073), \& Monongalia, WV (.049).

Panel (c): Median Hours at Home

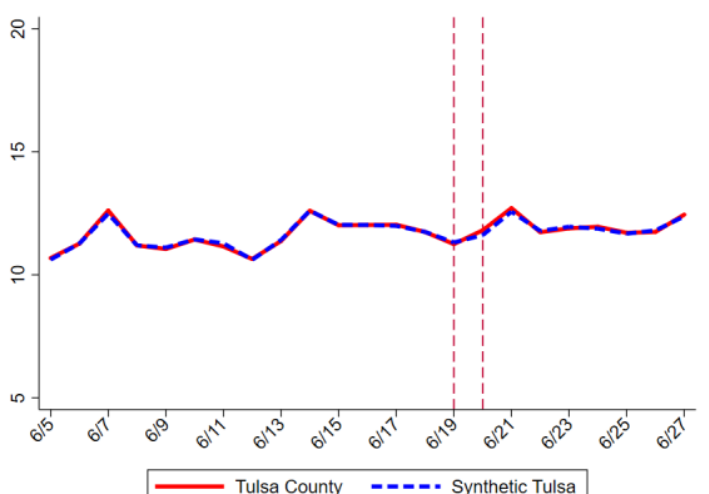

Note: Synthetic Tulsa is comprised of Dorchester, SC (.436), Silver Bow, MT (.126), Pima, AZ (.090), Linn, IA (.089), Lafayette, LA (.086), Anchorage, AK (.069), Johnson, IA (.067), \& Pinal, AZ (.033)

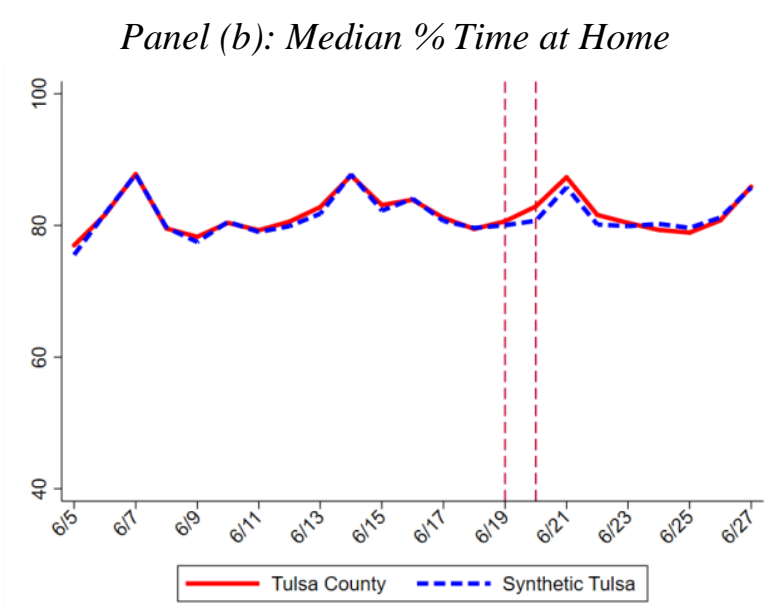

Note: Synthetic Tulsa is comprised of Chatham, GA (.329), Jefferson AL (.169), Cascade, MT (.159), Anchorage, AK (.14), Silver Bow, MT (.081), Coconino, AZ (.076), \& Athens, $\mathrm{OH}(.037)$.

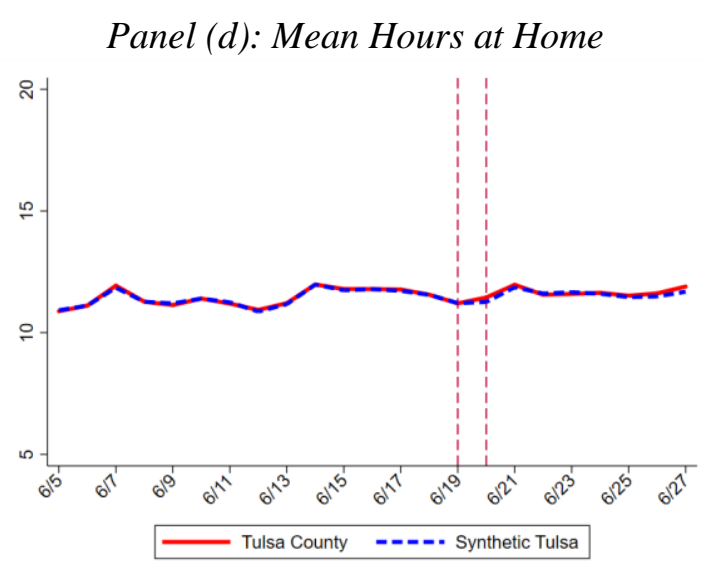

Note: Synthetic Tulsa is comprised of Dorchester, SC (.374), Anchorage, AK (.149), Jefferson, AL (.135), Pinal, AZ (.081), Silver Bow, AZ (.043), $\&$ Pottawattamie, IA (.038).

Note: The donor counties are comprised of counties with urbanicity rate of \pm 2.5 Tulsa County's urbanicity rate (95.2\%) or weighted population density of $\pm 1,000$ Tulsa County's density $(3,250)$ and exclude counties in Oklahoma and in Oklahoma's border states, as well as counties where a home resident was detected (via smartphone using SafeGraph data) in the treatment CBGs on June 20, 2020. Matching was based on six pre-treatment social distancing behaviors, COVID-19 testing rate, COVID-19 reopening policies, and mask wearing policies 


\section{Appendix Table 1. Synthetic Control Estimates of Effect of Tulsa Rally on Stay-at-Home}

Behavior

\begin{tabular}{|c|c|c|c|c|}
\hline & $\begin{array}{c}\% \text { Staying at } \\
\text { Home Full Time } \\
(1)\end{array}$ & $\begin{array}{c}\text { Median \% Time } \\
\text { at Home } \\
(2)\end{array}$ & $\begin{array}{c}\text { Median Hours } \\
\text { Spent at Home } \\
\text { (3) }\end{array}$ & $\begin{array}{c}\text { Mean Hours } \\
\text { Spent at Home } \\
\text { (4) }\end{array}$ \\
\hline & \multicolumn{4}{|c|}{ Panel I: Tulsa County and Border Counties } \\
\hline Trump Rally & 0.884 & 0.586 & -0.049 & -0.054 \\
\hline \multirow[t]{2}{*}{ P-Value } & {$[0.390]$} & {$[0.117]$} & {$[0.415]$} & {$[0.454]$} \\
\hline & \multicolumn{4}{|c|}{ Panel II: Tulsa County } \\
\hline Trump Rally & 1.135 & 0.795 & 0.054 & -0.003 \\
\hline P-Value & {$[0.152]$} & {$[0.270]$} & {$[0.727]$} & {$[0.537]$} \\
\hline
\end{tabular}

$*$ Significant at the $10 \%$ level, ** Significant at the 5\% level, *** Significant at the $1 \%$ level

Notes: Estimate is generated using synthetic control methods. The donor counties are comprised of counties with urbanicity rate of \pm 2.5 Tulsa County's urbanicity rate (95.2\%) or weighted population density of $\pm 1,000$ Tulsa County's density $(3,250)$ and exclude counties in Oklahoma and in Oklahoma's border states, as well as counties where a home resident was detected (via smartphone using SafeGraph data) in the treatment CBGs on June 20, 2020. All estimates match on six pre-treatment social distancing behaviors, COVID-19 testing rate, COVID-19 reopening policies, and mask wearing policies 
Appendix Table 2. Donor Pool that Received Positive Weights in Table 2

\begin{tabular}{|c|c|c|c|c|c|}
\hline \multicolumn{3}{|c|}{ COVID-19 Cases } & \multicolumn{3}{|c|}{ COVID-19 Deaths } \\
\hline$(1)$ & $(2)$ & $(3)$ & $(4)$ & $(5)$ & $(6)$ \\
\hline \multicolumn{6}{|c|}{ Panel I: Tulsa County } \\
\hline $\begin{array}{c}\text { La Crosse, WI (.430) } \\
\text { Clark, OH (.150) } \\
\text { Lafayette, LA (.143) } \\
\text { Jefferson, AL (.122) } \\
\text { Dorchester, SC (.116) } \\
\text { Pottawattamie, IA } \\
(.029)\end{array}$ & $\begin{array}{c}\text { La Crosse, WI (.356) } \\
\text { Jefferson, AL (.231) } \\
\text { Clark, OH (.140) } \\
\text { Dorchester, SC (.133) } \\
\text { Lafayette, LA (.074) } \\
\text { Story, IA (.064) }\end{array}$ & $\begin{array}{c}\text { La Crosse, WI (.394) } \\
\text { Weber, UT (.157) } \\
\text { Tulare, CA (.12) } \\
\text { Alachua, FL (.107) } \\
\text { Lafayette, LA (.102) } \\
\text { Charleston, SC (.056) } \\
\text { Story, IA (.031) } \\
\text { Pottawattamie, IA (.019) }\end{array}$ & $\begin{array}{c}\text { La Crosse, WI (.428) } \\
\text { Linn, IA }(.172) \\
\text { Jefferson, AL }(.166) \\
\text { Story, IA }(.125) \\
\text { Wayne, NE }(.045) \\
\text { Outagamie, WI }(.043)\end{array}$ & $\begin{array}{c}\text { La Crosse, WI (.421) } \\
\text { Jefferson, AL }(.214) \\
\text { Linn, IA (.150) } \\
\text { Tippecanoe, IN (.148) } \\
\text { Blair, PA (.052) }\end{array}$ & $\begin{array}{l}\text { Madera, CA (.413) } \\
\text { Osceola, FL (.183) } \\
\text { Lafayette, LA (.076) } \\
\text { Olmsted, MN }(.075) \\
\text { Schuykill, PA }(.055) \\
\text { Manatee, FL (.035) } \\
\text { St. John, LA (.016) }\end{array}$ \\
\hline \multicolumn{6}{|c|}{ Panel II: Tulsa County Cluster } \\
\hline $\begin{array}{c}\text { La Crosse, WI (.361) } \\
\text { Vanderburgh, IN } \\
\qquad .208) \\
\text { Clark, OH }(.181) \\
\text { Jefferson, AL }(.136) \\
\text { Lafayette, LA }(.093)\end{array}$ & $\begin{array}{c}\text { Jefferson, AL }(.275) \\
\text { La Crosse, WI (.207) } \\
\text { Ada, ID }(.13) \\
\text { Clark, OH }(.115) \\
\text { Linn, IA (.103) } \\
\text { Lafayette, LA (.097) } \\
\text { Cabell, WV (.073) }\end{array}$ & $\begin{array}{c}\text { Northumberland, PA (.325) } \\
\text { La Crosse, WI }(.308) \\
\text { Charleston, SC }(.132) \\
\text { Lafayette, LA }(.065) \\
\text { Muscogee, GA }(.051) \\
\text { Santa Barbara, CA (.050) } \\
\text { Tulare, CA }(.033) \\
\text { Weber, UT }(.032)\end{array}$ & $\begin{array}{c}\text { Wayne, NE }(.412) \\
\text { Linn, IA }(.234) \\
\text { Clarke, GA }(.166) \\
\text { Muscogee, GA }(.103) \\
\text { Poquoson, VA }(.040) \\
\text { Jefferson, AL }(.036)\end{array}$ & $\begin{array}{c}\text { Cabell, WV (.288) } \\
\text { Linn, IA (.274) } \\
\text { Clarke, GA (.161) } \\
\text { Muscogee, GA (.133) } \\
\text { Clark, OH (.099) } \\
\text { Jefferson, AL (.023) } \\
\text { Wayne, NE (.023) }\end{array}$ & $\begin{array}{c}\text { Madera, CA }(.500) \\
\text { Canyon, ID }(.225) \\
\text { Colonial Height, VA } \\
\quad(.086) \\
\text { Eau Claire, WI (.062) } \\
\text { Manatee, FL (.036) } \\
\text { Kenton, KY (.034) } \\
\text { Orange, NY }(.019)\end{array}$ \\
\hline \multicolumn{6}{|c|}{ Panel III: State of Oklahoma } \\
\hline $\begin{array}{l}\text { ID (.610) } \\
\text { SC (.222) } \\
\text { MT (.168) }\end{array}$ & $\begin{array}{l}\text { ID (.606) } \\
\text { SC (.224) } \\
\operatorname{MT~(.17)~}\end{array}$ & $\begin{array}{l}\text { ID (.602) } \\
\text { SC (.222) } \\
\text { MT (.175) }\end{array}$ & $\begin{array}{l}\text { MT }(.511) \\
\text { ID }(.257) \\
\text { MI }(.098) \\
\text { WY }(.085) \\
\text { AL }(.049)\end{array}$ & $\begin{array}{l}\text { MT }(.442) \\
\text { ID }(.364) \\
\text { MI }(.094) \\
\text { WY }(.057) \\
\text { AL }(.043)\end{array}$ & $\begin{array}{l}\text { WY }(.362) \\
\text { AK }(.279) \\
\text { MT }(.159) \\
\text { ND }(.098) \\
\text { MI }(.062) \\
\text { IA }(.041)\end{array}$ \\
\hline
\end{tabular}

Observables used to construct the weights

Number of pre-treatment days

Matching on pre-treat Median Hours at Home

Matching on Reopening Policy?

Matching on Mask Wearing Policy?

Matching COVID-testing?

\begin{tabular}{cccccc}
6 & 6 & 14 & 6 & 6 & 14 \\
Yes & Yes & No & Yes & Yes & Yes \\
Yes & Yes & No & Yes & No \\
Yes & Yes & No & Yes & No \\
No & Yes & No & No & Yes & No \\
\hline
\end{tabular}




\section{Appendix Table 3. Synthetic Control Estimates of Effect of Tulsa Rally on Three-day Moving Average of COVID-19 Case Growth Rate}

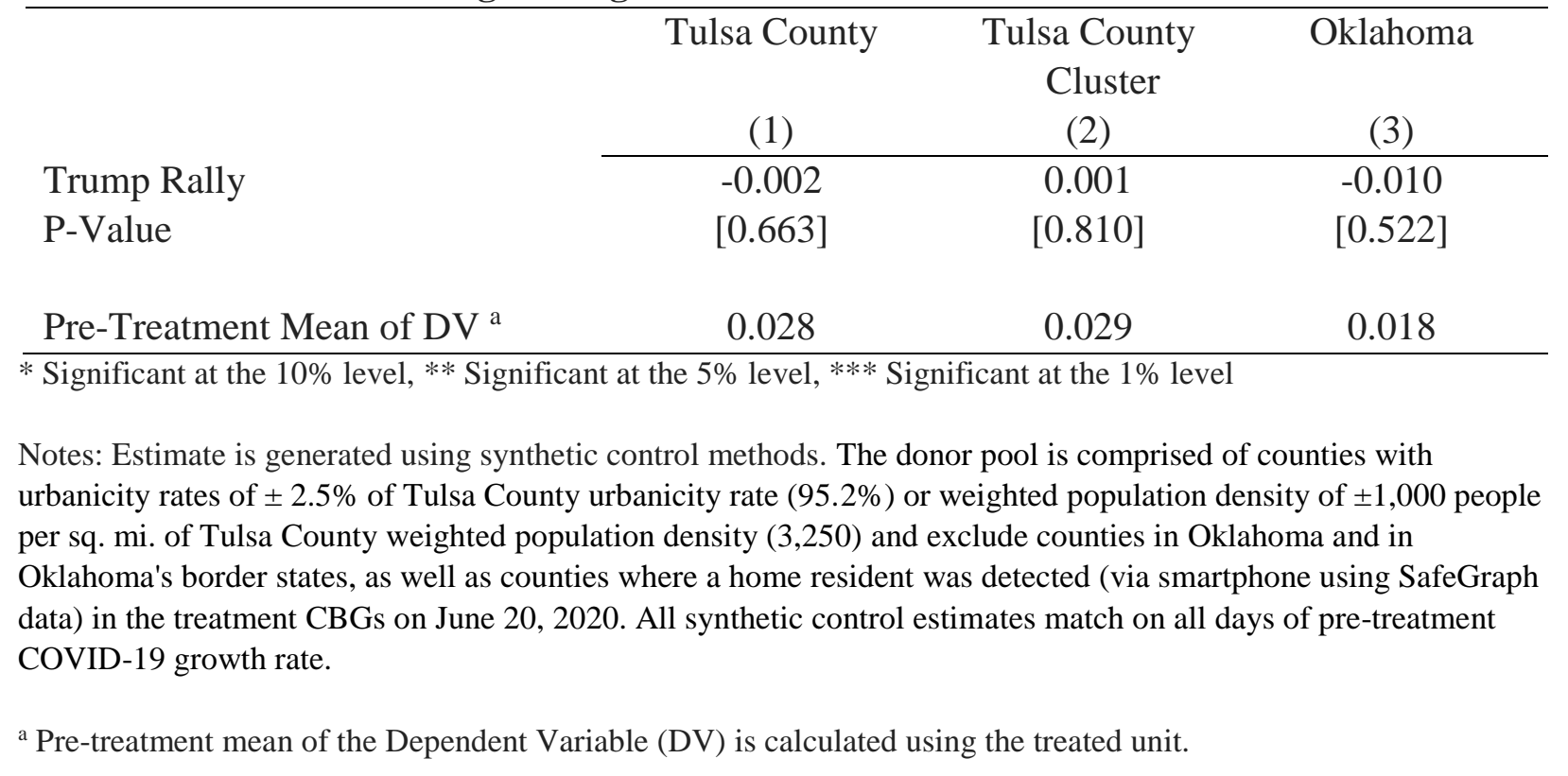




\section{Appendix Table 4. Synthetic Control Estimates of Effect of Tulsa Rally on COVID-19 Case and Death Rate Using Different Donor Pools}

Cases per 100,000

(1)

(2)
Deaths per 100,000

(3)

\begin{tabular}{|c|c|c|c|c|}
\hline \multirow[b]{2}{*}{ Trump Rally } & \multicolumn{4}{|c|}{ Panel I: Tulsa County } \\
\hline & -57.201 & -104.822 & 0.330 & -0.541 \\
\hline P-Value & {$[0.411]$} & {$[0.240]$} & {$[0.667]$} & {$[0.760]$} \\
\hline \multirow[t]{2}{*}{ Pre-Treatment Mean of DV ${ }^{\mathrm{a}}$} & 230.099 & 230.099 & 9.542 & 9.542 \\
\hline & \multicolumn{4}{|c|}{ Panel II: Tulsa Cluster } \\
\hline Trump Rally & 29.159 & -115.975 & 0.143 & -1.114 \\
\hline P-Value & {$[0.494]$} & {$[0.100]$} & {$[0.944]$} & {$[0.400]$} \\
\hline \multirow[t]{2}{*}{ Pre-Treatment Mean of DV ${ }^{\mathrm{a}}$} & 227.892 & 227.892 & 13.210 & 13.210 \\
\hline & \multicolumn{4}{|c|}{ Panel III: State of Oklahoma } \\
\hline Trump Rally & -73.154 & -111.668 & 0.318 & 0.187 \\
\hline P-Value & {$[0.364]$} & {$[0.174]$} & {$[0.409]$} & {$[0.434]$} \\
\hline Pre-Treatment Mean of DV ${ }^{\mathrm{a}}$ & 203.002 & 203.002 & 9.044 & 9.044 \\
\hline $\begin{array}{l}\text { Weight Population Density Cut } \\
\text { for Donor Pool }\end{array}$ & Yes & No & Yes & No \\
\hline Urbanicity Cut for Donor Pool & No & Yes & No & Yes \\
\hline
\end{tabular}

Panel I: Tulsa County

Trump Rally

P-Value

* Significant at the $10 \%$ level, ** Signif

Note: Estimate is generated using synthetic control method. Matching was based on six days of pre-treatment COVID-19 case rates, pre-treatment stay-at-home behavior, COVID-19 testing rate, COVID-19 reopening policy, and mask wearing policy. Donor pool is restricted to counties/states with similar weight population or urbanicity as Tulsa/Oklahoma. 